\title{
Overview of the Neuroprotective Effects of the MAO-Inhibiting Antidepressant Phenelzine
}

\author{
Dmitriy Matveychuk ${ }^{1}$ - Erin M. MacKenzie ${ }^{1}$. David Kumpula ${ }^{1} \cdot$ Mee-Sook Song ${ }^{1,2}$. Andrew Holt ${ }^{1}$. Satyabrata Kar ${ }^{1,3}$. \\ Kathryn G. Todd ${ }^{1} \cdot$ Paul L. Wood ${ }^{4}$. Glen B. Baker ${ }^{1}[$
}

Received: 29 December 2020 / Accepted: 10 March 2021 / Published online: 10 April 2021

(c) The Author(s) 2021

\begin{abstract}
Phenelzine (PLZ) is a monoamine oxidase (MAO)-inhibiting antidepressant with anxiolytic properties. This multifaceted drug has a number of pharmacological and neurochemical effects in addition to inhibition of MAO, and findings on these effects have contributed to a body of evidence indicating that PLZ also has neuroprotective/neurorescue properties. These attributes are reviewed in this paper and include catabolism to the active metabolite $\beta$-phenylethylidenehydrazine (PEH) and effects of PLZ and PEH on the GABA-glutamate balance in brain, sequestration of reactive aldehydes, and inhibition of primary amine oxidase. Also discussed are the encouraging findings of the effects of PLZ in animal models of stroke, spinal cord injury, traumatic brain injury, and multiple sclerosis, as well other actions such as reduction of nitrative stress, reduction of the effects of a toxin on dopaminergic neurons, potential anticonvulsant actions, and effects on brain-derived neurotrophic factor, neural cell adhesion molecules, an anti-apoptotic factor, and brain levels of ornithine and $\mathrm{N}$-acetylamino acids.
\end{abstract}

Keywords Phenelzine $\cdot$ Monoamine oxidase $\cdot \beta$-Phenylethylidenehydrazine $\cdot$ Neuroprotection $\cdot \gamma$-Aminobutyric acid $\cdot$ Reactive aldehydes

\begin{tabular}{|c|c|c|c|}
\hline \multicolumn{2}{|c|}{ Abbreviations } & DOPEGAL & 3,4-Dihydroxyphenylglycolaldehyde \\
\hline 3-AP & 3-Aminopropanal & EAE & Experimental autoimmune \\
\hline $\mathrm{AD}$ & Alzheimer's disease & & encephalomyelitis \\
\hline \multirow[t]{2}{*}{ ADAM-10 } & A disintegrin and metalloproteinase domain- & FADD & Fas-associated drug domain \\
\hline & containing protein $10 ; \alpha$-secretase & GABA & $\gamma$-Aminobutyric acid \\
\hline AP-2 & Adaptor protein complex-2 & GABA-T & GABA transaminase \\
\hline APP/PS1 & Amyloid precursor protein/presenilin 1 & $\mathrm{H}_{2} \mathrm{O}_{2}$ & Hydrogen peroxide \\
\hline ATP & Adenosine triphosphate & HIAL & 5-Hydroxyindoleacetaldehyde \\
\hline BACE & $\beta$-Secretase & HNE & 4-Hydroxy-2-nonenal \\
\hline \multirow[t]{2}{*}{ CCI-TBI } & Controlled cortical impact traumatic brain & L1 & Neuronal cell adhesion molecule \\
\hline & injury & MAO & Monoamine oxidase \\
\hline CSF & Cerebrospinal fluid & $\mathrm{MPP}^{+}$ & 1-Methyl-4-phenylpyridinium \\
\hline DOPAL & 3,4-Dihydroxphenylacetaldehyde & MPTP & 1-Methyl-4-phenyl-1,2,3,6-tetrahydropyri- \\
\hline \multirow{2}{*}{\multicolumn{2}{|c|}{$\begin{array}{l}\text { Glen B. Baker } \\
\text { glen.baker@ualberta.ca }\end{array}$}} & PD & Parkinson's disease \\
\hline & & $\mathrm{PEH}$ & $\beta$-Phenylethylidenehydrazine \\
\hline 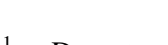 & & PLZ & Phenelzine \\
\hline \multirow{2}{*}{\multicolumn{2}{|c|}{$\begin{array}{l}\text { Department of Psychiatry (Neurochemical Research Unit), } \\
\text { University of Alberta, 12-105B Clinical Sciences Building, } \\
\text { Edmonton, AB T6G 2G3, Canada }\end{array}$}} & PrAO & Primary amine oxidase \\
\hline & & ROS & Reactive oxygen species \\
\hline \multirow{2}{*}{\multicolumn{2}{|c|}{ Present Address: Altos Biologics, Seoul, South Korea }} & SCI & Spinal cord injury \\
\hline 1 Heschit & & SSAO & Semicarbazide-sensitive amine oxidase \\
\hline \multirow{2}{*}{\multicolumn{2}{|c|}{$\begin{array}{l}\text { Department of Medicine (Neurology), University of Alberta, } \\
\text { Edmonton, Canada }\end{array}$}} & TBI & Traumatic brain injury \\
\hline College o & & TRKB & Tropomyosin-related kinase B \\
\hline \multicolumn{2}{|c|}{$\begin{array}{l}\text { College of Veterinary Medicine, Lincoln Memorial } \\
\text { University, Harrogate, TN, USA }\end{array}$} & TRPA1 & Transient receptor potential ankyrin 1 \\
\hline
\end{tabular}


VAP-1 Vascular adhesion protein

VGLUT Vesicular glutamate transporter

\section{Introduction}

In the last 25 years, numerous exciting research reports have demonstrated that many antidepressants and antipsychotics have neuroprotective and/or neurorescue properties (Baker et al. 2012; Chen and Nasrallah 2019; Hunsberger et al. 2009; Li and Xu 2007; Lieberman et al. 2008; Shadfar et al. 2018; Song et al. 2013; Sowa et al. 2004; Tatton et al. 2003; $\mathrm{Xu}$ et al. 2003; Youdim and Bakhle 2006; Young 2002). With regard to monoamine oxidase inhibitors (MAOIs), much of this research has focused on the selective irreversible MAO-B inhibitors L-deprenyl and rasagaline, which have demonstrated neuroprotective properties in a wide variety of models in vitro and in vivo (Gerlach et al. 1996; Hill et al. 2020; Magyar and Szende 2004; Sowa et al. 2004; Szökő et al. 2018; Tatton et al. 2003; Youdim et al. 2006). However, there is also extensive research demonstrating multiple actions of the MAOI phenelzine (PLZ) that may contribute to neuroprotection/neurorescue, and the focus of the current review paper is on PLZ and its numerous properties in that regard.

PLZ (Fig. 1) is a non-selective (inhibits both MAO-A and -B) irreversible MAOI marketed as an antidepressant, but it has also been reported in clinical studies to be effective in treatment of anxiety disorders such as panic disorder and social anxiety disorder (Aarre 2003; Buigues and Vallejo 1987; Davidson et al. 1987; Liebowitz et al. 1988; McGrath et al. 1986; Sheehan et al. 1980; Williams et al. 2020; Zhang and Davidson 2007). As with other irreversible non-subtype-selective MAO inhibitors, some dietary restrictions are recommended for patients on PLZ to avoid a potential hypertensive crisis when certain foods are ingested, although effects on blood pressure appear to be less problematic than originally proposed in the literature (see Gillman 2018 for discussion of this aspect). PLZ is a multifaceted drug that acts on several enzymes and other factors proposed to be involved in neuroprotection and in the etiology of a variety of psychiatric and neurological disorders (Al-Nuaimi et al. 2012; Baker et al. 1991, 2019; Hill et al. 2020; Holt et al. 2004; Jarrahi et al. 2020; MacKenzie et al. 2010; Popov and Matthies 1969; Ribaudo et al. 2020; Song et al. 2010; Wood et al. 2006b). The following aspects which appear to be contributing to the neuroprotective effects of PLZ will be discussed in detail in this review: contribution of an active metabolite; inhibition of MAO; inhibition of $\gamma$-aminobutyric acid transaminase (GABA-T) and elevation of brain GABA levels; elevation of brain levels of the amino acid ornithine and $\mathrm{N}$-acetylamino acids; sequestration of toxic reactive aldehydes such as formaldehyde, acrolein, 3-aminopropanal, malondialdehyde, and 4-hydroxy-2-nonenal (4-HNE); and inhibition of primary amine oxidase [PrAO, also known as semicarbazide-sensitive amine oxidase (SSAO)]. Some recent findings on additional factors that may be involved in its neuroprotective actions will also be discussed.

In preparation for this review paper, the Web of Science databases and PubMed were reviewed for papers from the years 1995 to 2020 . The following search headings were used: phenelzine and neuroprotection; phenelzine and oxidative stress; reactive aldehydes in psychiatric disorders; reactive aldehydes in neurological disorders; acrolein in disease states; semicarbazide-sensitive amine oxidase in disease states; semicarbazide-sensitive amine oxidase in Alzheimer's disease; and primary amine oxidase in Alzheimer's disease. The reference lists in a number of papers on the above topics were also searched for additional appropriate references, and we have also included results from our own investigations on PLZ.

\section{$\beta$-Phenylethylidenehydrazine (PEH), an Active Metabolite of PLZ}

PLZ is metabolized extensively, with metabolites including $\beta$-phenylethylamine, phenylacetic acid, $p$-hydroxyphenylacetic acid, $\beta$-phenylethylidenehydrazine (PEH), and phenylethyldiazene (Clineschmidt and Horita 1969a, 1969b;

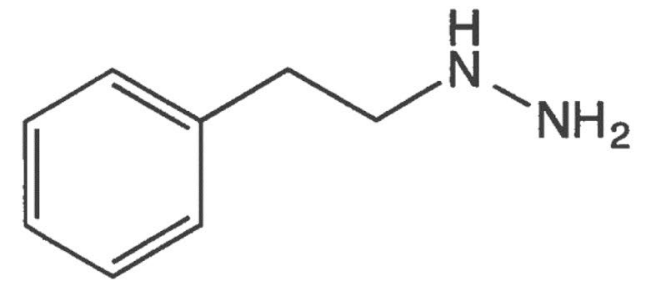

Phenelzine

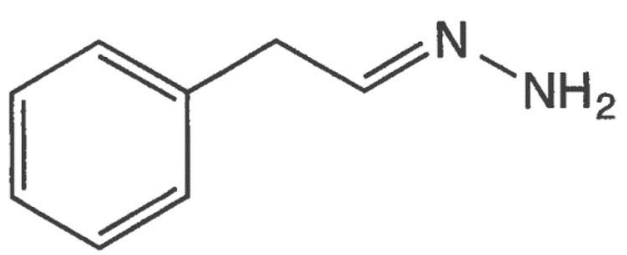

PEH

Fig. 1 Chemical structures of PLZ and PEH 
Kennedy et al. 2009; Kumpula et al. 2010; Robinson et al. 1985; Tipton 1972; Tipton and Spires 1972). Of these, PEH (Fig. 1) appears to contribute markedly to the neuroprotective effects of the parent drug. In addition to being inhibited by PLZ, MAO also catalyzes the catabolism of PLZ (Clineschmidt and Horita 1969a, 1969b; Horita 1965; Popov and Matthies 1969; Tipton 1971, 1972), with PEH being a prominent metabolite (Patek and Hellerman 1974; Tipton and Spires 1972). Although PEH is only a weak inhibitor of MAO (MacKenzie et al. 2008a; Matveychuk 2015; Matveychuk et al. 2013; Paslawski et al. 2001), it has several actions, including effects on brain levels of GABA, sequestration of reactive aldehydes, and inhibition of PrAO that may contribute to the neuroprotective/neurorescue properties of PLZ, and these actions will be described in the appropriate sections below.

\section{Inhibition of MAO-A and MAO-B}

By inhibiting MAO, PLZ elevates brain levels of the monoamine neurotransmitters 5-hydroxytryptamine (5-HT, serotonin), noradrenaline, and dopamine which have been proposed to be functionally deficient in depression (reviews: Baker and Dewhurst 1985; Blier 2016). However, the inhibition of MAO may also be associated with some of the neuroprotective properties of PLZ. The catalytic cycle of MAO results in the production of $\mathrm{H}_{2} \mathrm{O}_{2}$, an aldehyde (via an imine) and ammonia (for primary amines) or an alkyl-substituted amine (for secondary and tertiary amines). Ammonia, $\mathrm{H}_{2} \mathrm{O}_{2}$, and some of the aldehyde metabolites formed are potentially neurotoxic (Marchitti et al. 2007; Wang et al. 2004; Wood et al. 2007a; Yang 2004; Yang et al. 2003), and their production is reduced by MAOIs. The MAO-catalyzed oxidation of catecholamines and 5-HT results in formation of 3,4-dihydroxyphenylacetaldehyde (DOPAL) from dopamine, 3,4-dihy droxyphenylglycolaldehyde (DOPEGAL) from noradrenaline and adrenaline, and 5-hydroxyindoleacetaldehyde (5-HIAL) from 5-HT. These three aldehydes have been reported to produce toxicity in a variety of in vitro and in vivo experiments (Cagle et al. 2019; Eisenhofer et al. 2004; Marchitti et al. 2007) and have been implicated in the etiology of Alzheimer's disease (AD) and Parkinson's disease (PD) (Burke et al. 2003, 2004; Grünblatt et al. 2004; Masato et al. 2019; Panneton et al. 2010).

It has been reported that with aging in humans there is increased brain activity of MAO-B, but not of MAO-A (Fowler et al. 1997, 2002; Shemyakov 2001; Volchegorskii et al. 2001). The activity of MAO-B is also increased in brains of $\mathrm{AD}$ patients relative to age-matched controls, while MAO-A activity has been reported to be unchanged or increased depending on the brain regions under investigation (Adolfsson et al. 1980; Jossan et al. 1991; Oreland and
Gottfries 1986; Quartey et al. 2018; Reinikainen et al. 1988; Saura et al. 1994; Sherif et al. 1992; Sparks et al. 1991). The increased MAO-B activity in aging and AD may be the result of age- and neurodegeneration-related proliferation of glial cells since MAO-B is expressed in glia (Beach et al. 1989; Liu et al. 1996; Riederer et al. 1987). This increase in MAO-B activity has been proposed to contribute to destruction of cholinergic neurons, cognitive dysfunction, and formation of amyloid plaques and neurofilbrillary tangles (Cai 2014; Manzoor and Hoda 2020; Schedin-Weiss et al. 2017). The mechanism of the effect of MAO-B on cholinergic neurons is unclear, but may be the result of the excess MAO-B producing increased levels of hydrogen peroxide, subsequently leading to formation of reactive oxygen species such as the hydroxyl radical (Practico 2008; Quartey et al., 2018; Riederer et al. 2004; Sturm et al. 2017; Sa et al. 2019). Interestingly, Jossan et al (1989), in a study with a cholinergic neurotoxin in rats reported that degeneration of cholinergic neurons also results in an increase in activity of MAO-B, but not of MAO-A, in hippocampus, striatum, and cortex. These authors suggested that the increase was due to increased gliosis after cholinergic neuronal degeneration and that increased MAO-B activity may reflect degeneration of the cholinergic system. It has also been proposed that MAO-B may increase neurodegeneration via regulation of $\beta$-amyloid levels by activating $\gamma$-secretase in neurons (Schedin-Weiss et al. 2017). An interaction of MAO-B with GABA may also contribute to the cognitive dysfunction seen in AD. MAO-B has been reported to catalyze formation of GABA from the polyamine putrescine in glia, and the GABA thus formed is released to mediate tonic inhibition (Yoon et al. 2014). The presence of reactive astrocytes in close proximity to amyloid plaques has been observed in $\mathrm{AD}$, and it has been proposed that aberrant levels of GABA formed by the action of MAO-B in such astrocytes impair memory in mouse models of AD (Jo et al. 2014).

MAOIs would attenuate the effects of increased MAO-B, although they have not been utilized extensively in treatment of $\mathrm{AD}$; such studies have been conducted mainly with irreversible MAO-B inhibitors such as selegiline and rasagiline, and the results in long-term studies have been generally disappointing (Park et al., 2019; Schneider et al. 2014; Tabi et al. 2020). Park et al. (2019) proposed that the MAO-B/ GABA interaction may account for why the irreversible MAO-B-selective inhibitor L-deprenyl (selegiline) has been found to improve cognitive deficits in AD after short-term, but not long-term, administration. In studies on the amyloid precursor, protein/presenilin 1 (APP/PS1) mouse model of $\mathrm{AD}$, these researchers found that selegiline reduced the aberrant levels of GABA initially by inhibiting MAO-B but that increased activity of the compensatory GABA-synthesizing enzyme diamine oxidase after longer administration of selegiline resulted in increased levels of GABA again; they 
found that a highly selective, reversible MAO-B inhibitor (KDS2010) did not have this effect and reversed learning and memory impairment in this mouse model (Park et al 2019). Because of their effects on reactive oxygen species, toxic aldehydes, and PrAO (see the following discussions in this review), PLZ and PEH might be useful adjunctive drugs to study in AD, although their GABA-enhancing effects (see next section) may contribute to memory impairment (Park et al. 2019).

\section{Elevation of Brain Levels of GABA by PLZ and PEH}

Although it was developed as an MAOI, it is well documented that PLZ also causes an elevation of brain levels of GABA in rats (Baker et al. 1991; McKenna et al. 1994; Paslawski et al. 1995; Popov and Matthies 1969; Todd and Baker 1995; Fig. 2). In 1969 Popov and Matthies reported that the treatment of rats with another MAOI before administering PLZ attenuated the ability of PLZ to elevate brain levels of GABA, suggesting that a metabolite formed by the action of MAO on PLZ was responsible for the observed effects. Since PEH had been reported as a metabolite of PLZ (Patek and Hellerman 1974; Tipton and Spires 1972), we synthesized PEH, which differs structurally from PLZ in the presence of a double bond. We found that PEH, like PLZ, caused a rapid, marked, and relatively long-lasting elevation of brain GABA after a single intraperitoneal (ip) injection to rats (MacKenzie et al. 2010; Paslawski et al. 2001). While PEH is a weak MAO inhibitor (MacKenzie et al. 2010; Matveychuk et al. 2013; Paslawski et al. 2001), this metabolite inhibits GABA transaminase (GABA-T) (Paslawski et al. 2001; MacKenzie et al. 2008a), presumably contributing to the GABA-elevating action of PLZ.

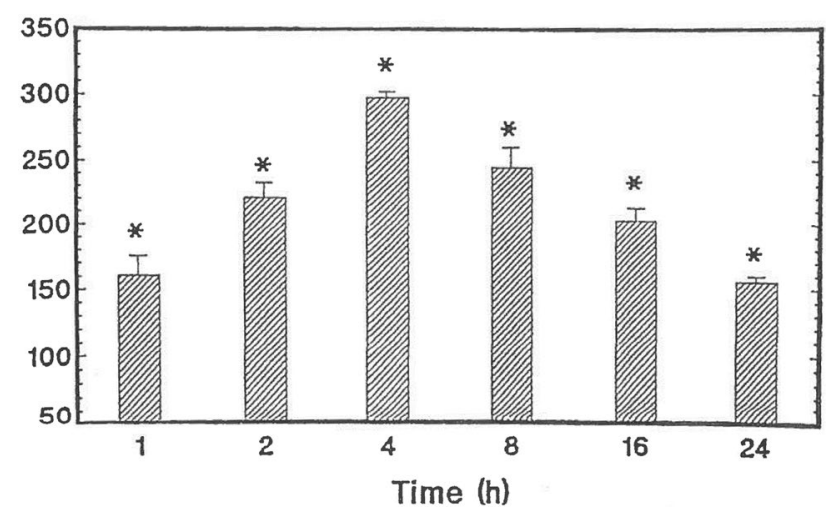

Fig. 2 Effects of PLZ (15 mg/kg ip) on rat whole brain levels of GABA (from Baker et al. 1991 with permission from Elsevier). Values represent mean $\%$ of controls \pm SEM $(N=5)$. Control GABA values $=234 \pm 8 \mu \mathrm{g} / \mathrm{g}(N=30)$. $* p<0.05$ compared to control values
Our interest in possible neuroprotective/neurorescue actions of PLZ and PEH was stimulated by reports that various GABAergic drugs decreased neuronal cell loss in animal models of stroke (global and focal ischemia) (Chen Xu et al. 2000; Leker and Neufeld 2003; Shuaib et al. 1992, 1997; Shuaib and Kanthan 1997; Sydserff et al. 2000) and by suggestions that such agents were effective by counteracting the deleterious excitotoxic effects of the increased glutamate release that occurs in stroke (Green et al. 2000; Schwartz-Bloom and Sah 2001; Shuaib and Kanthan 1997; Stumm et al. 2001). Indeed, there is now a large body of literature indicating the importance of maintaining the exquisite balance between GABA and glutamate in the brain and suggesting that a disruption of that balance is a feature of several psychiatric and neurological disorders, including depression, mania, epilepsy, amyotrophic lateral sclerosis, schizophrenia, multiple sclerosis, and stroke (Cohen et al. 2015; Foerster et al. 2013; Green et al. 2000; Ketter and Wang 2003; Kim and Yoon 2017; Luscher et al. 2011; Naylor 2010; Potter et al. 2016; Wassef et al. 2003). We tested PLZ and PEH in a global ischemia model in the gerbil (the animal model that is used primarily in such studies) and found marked neurorescue effects with each of these drugs at doses which caused pronounced increases in brain levels of GABA (Sowa et al. 2003, Sowa et al. 2005; Tanay et al. 2002; Todd et al. 1999; Wood et al. 2006b and Fig. 3).

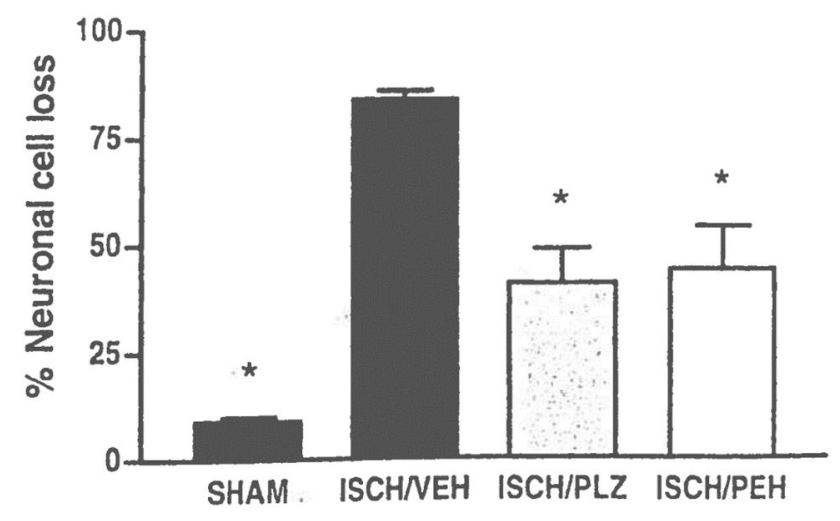

Fig. 3 Attenuation by PLZ and PEH of neuronal loss in a global ischemia model of stroke (carotid ligation for $5 \mathrm{~min}$ followed by reperfusion). PLZ (15 mg/kg ip) or PEH (30 mg/kg ip) were started $3 \mathrm{~h}$ post reperfusion. Gerbils were treated once daily at the same dose for 6 days and were euthanized $24 \mathrm{~h}$ after the last dose. Neuronal cell counts were obtained in the hippocampal CA1 region. * $p<0.05$ compared to values in the ischemia-vehicle gerbils. $N=6$ for drug-treated gerbils and $N=12$ for SHAM and ISCH/VEH gerbils 


\section{Sequestration of Reactive Aldehydes by PLZ and PEH}

Another important concept which is of considerable interest with regard to possible neuroprotective mechanisms of action of PLZ, PEH, and structurally related drugs is their attenuation of "aldehyde overload", i.e., excessive levels of toxic reactive aldehydes (Wood 2006; Wood et al. 2006b). Through Michael addition and/or formation of a Schiff base, aldehydes can form adducts with and cross-link proteins, nucleic acids, and aminophospholipids (Esterbauer et al. 1991), leading to a variety of adverse effects. This may result in inhibition of DNA, RNA, and protein synthesis, disruption of protein and cell membrane function, dysfunction of calcium homeostasis, and interference with pathways regulating cell respiration and glycolysis (Dang et al. 2010; Esterbauer et al. 1991; Lovell et al. 2001; Wood et al. 2006b).

There has been a great deal of research in the last two decades focusing on the role of toxic reactive aldehydes in neurodegeneration (Chen et al. 2016a; Matveychuk et al. 2011; Moghe et al. 2015; Ng et al. 2008; Perluigi et al. 2012; Romano et al. 2017; Sultana et al. 2013; Taso et al. 2019; Xiao et al. 2017). Potential sources of these aldehydes include lipid peroxidation as a result of oxidative stress, carbohydrate autoxidation and metabolism, cytochrome P450-mediated oxidation of alcohols, myeloperoxidase-mediated oxidation of amino acids, and catalytic activity of amine oxidases (O'Brien et al. 2005; Wood et al. 2006a). Production of acrolein, malondialdehyde and 4-hydroxy-2-nonenal (4-HNE) may result from lipid peroxidation (Esterbauer et al. 1991; Lee and Park 2013; Ou et al. 2002; Reed 2011; Uchida et al. 1998; Yadav and Ramana 2013). As mentioned above, DOPAL, DOPEGAL and 5-HIAL result from the oxidation of catecholamines and 5-HT by MAO (Eisenhofer et al. 2004; Marchitti et al. 2007). Several possible enzymes may oxidize polyamines, resulting in generation of 3-aminopropanal (3-AP) and acrolein (Agostinelli et al. 2010; Houen et al. 1994; Wood et al. 2006b, 2007a), and formaldehyde and methylglyoxal are generated by oxidation of methylamine and aminoacetone, respectively, by PrAO (Lyles and Chalmers 1992; Lyles et al. 1990). Accumulation of reactive aldehydes and resultant toxicity can occur because of reduced catabolism by enzymes such as glutathione- $S$-transferase, aldehyde dehydrogenase, and aldo-keto reductase (Ivanova et al. 1998; Wood et al. 2007b). Accumulation of reactive aldehydes also results in depletion of intracellular thiols that sequester the aldehydes, particularly the major intracellular antioxidants glutathione and cysteine (Wood et al. 2007b). Clinically, this reduction in cellular thiols has been reported in schizophrenia (Wood and Wood 2013).
There have been reports of elevated levels of malondialdehyde and acrolein in the plasma, serum, erythrocytes, and brains of AD patients (Casado et al. 2008; Greilberger et al. 2008; Gustaw-Rothenberg et al. 2010; Lovell et al. 2001; Marcus et al. 1998; Martin-Aragon et al. 2009; Nam et al. 2010; Padurariu et al. 2010; Sinem et al. 2010). Levels of 4-HNE have been reported to be increased in brain tissue and cerebrospinal fluid (CSF) of AD patients, and this aldehyde has been found to be present in the neurofibrillary tangles and senile plaques of AD (Zarkovic 2003). Increases in levels of reactive aldehydes including acrolein and 4-HNE have also been reported in the central nervous system of individuals showing early signs of AD (Bradley et al. 2010; Moghe et al. 2015; Williams et al. 2006), suggesting that perhaps an early event in the development of AD could be accumulation of reactive aldehydes. Such aldehydes have been found to play a potential role in prominent aspects of AD. Malondialdehyde, formaldehyde, and methylglyoxal have been reported to increase the rate of amyloid- $\beta(A \beta)$ oligomer and protofibril formation and to increase the size of the aggregates (Chen et al. 2006). Chronic exposure of rats to acrolein has been reported to result in mild cognitive decline with neuronal loss and activation of astrocytes in the hippocampus; these researchers also observed upregulation of cortical levels of $\beta$-secretase (BACE-1, the enzyme catalyzing formation of $A \beta$ from APP) and downregulation of levels of $\alpha$-secretase [A disintegrin and metalloproteinase domain-containing protein 10; (ADAM-10), responsible for production of a non-amyloidogenic peptide fragments from APP] in the hippocampus and cortex (Huang et al. 2013). Khoramjouy et al. (2020) reported that chronic oral administration of acrolein to rats resulted in impaired learning and memory and that there was a direct correlation between that impairment and the CSF levels of acrolein. Hyperphosphorylation of tau protein and acceleration of tau aggregation into fibrils have been reported to be induced by acrolein and methylglyoxal (Gomez-Ramos et al. 2003; Kuhla et al. 2007; Li et al. 2012). In late stage AD, when oxidative stress is very advanced, increases in levels of malondialdehyde, acrolein and 4-HNE are very evident (Bradley et al. 2010; Casado et al. 2008).

Elevated malondialdehyde levels have been observed in plasma and cerebrospinal fluid of PD patients (Baillet et al. 2010; Chen et al. 2009; Ilic et al. 1999; Serra et al. 2009), and 4-HNE and malondialdehyde adducts have been found in Lewy bodies in neocortical and brain stem neurons in PD (Zarkovic 2003). Increased malondialdehyde and acrolein content in the substantia nigra has also been reported in PD (Dexter et al. 1989; Shamoto-Nagai et al. 2007). Reactive aldehyde accumulation may be an early step in disease development in PD since increased levels of malondialdehyde adducts in several brain regions of individuals with early stages of PD neuropathology have been reported 
(Dalfo et al. 2005). Acrolein was found to be colocalized with $\alpha$-synuclein in substantia nigra neurons of PD patients; the acrolein was shown to enhance $\alpha$-synuclein oligomerization in vitro in dopaminergic neurons, which can result in mitochondrial dysfunction (Shamoto-Nagai et al. 2007). In addition, Dalfo and Ferrer (2008) discovered malondialdehyde-modified $\alpha$-synuclein in the substantia nigra and frontal cortex of PD patients, and of individuals with preclinical PD.

A key feature of several psychiatric (Buckley 2019; Troubat et al. 2020; Zuliani et al. 2007) and neurodegenerative (Phani et al. 2012; Schain and Kreisl 2017; Wood et al. 1993; Wood 2003) diseases is sustained neuroinflammation that is hypothesized to lead to neuronal dysfunction. It remains to be determined if reactive aldehydes are initiators of these inflammatory cascades or are stimulated by the cascades and thereby contribute to the activated immune response.

Hydroxylamines and mercapto compounds are known to "mop up" or sequester reactive aldehydes through a chemical reaction (Wood et al. 2006a), but several of these compounds are toxic in their own right. Hydrazines with an unsubstituted $\mathrm{NH}_{2}$ group are also known to react with aldehydes (Fig. 4) to produce non-toxic hydrazones. PLZ and PEH are such hydrazines and would be expected to be useful drugs for reducing levels and toxicity of such aldehydes.

We conducted a study on the effects of PLZ on the toxic actions of 3-AP and acrolein in retinal ganglion cell cultures and found it to be a potent neuroprotective agent and we have demonstrated, using mass spectrometry, that it does sequester 3-AP under the incubation conditions used (Wood et al. 2007a; Fig. 5). In other studies, we found that PLZ and $\mathrm{PEH}$ attenuate the reduction in viability of cultured mouse cortical neurons produced by acrolein (Baker et al. 2019)<smiles>NNCCc1ccccc1</smiles>

Phenelzine

PEH

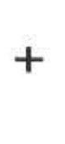<smiles>CC(C)=O</smiles>

Aldehyde

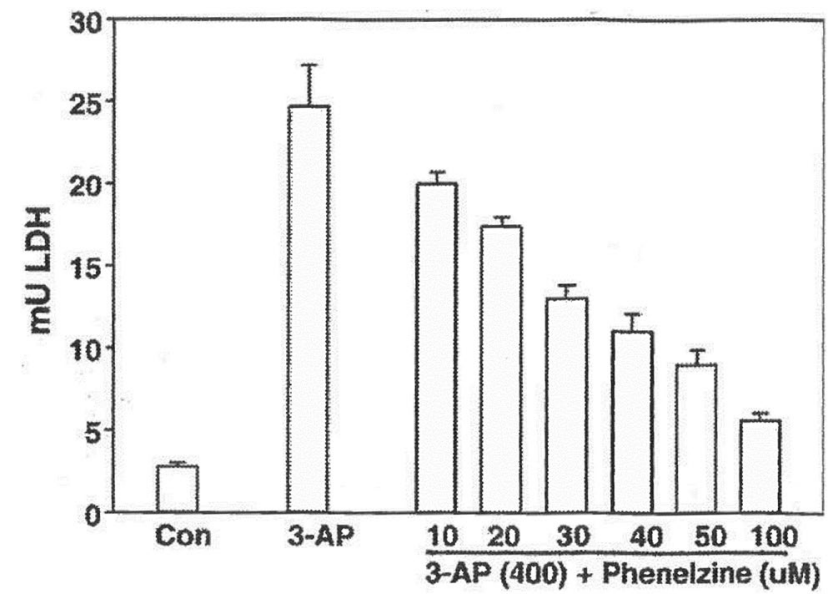

Fig. 5 Results from a concentration-response study on effects of PLZ on 3-AP-induced toxicity in rat retinal ganglia cells (from Wood et al. 2006a with permission from Elsevier). PLZ was added as a cotreatment with 3-AP; media were assayed for LDH $24 \mathrm{~h}$ later

and sequester several reactive aldehydes in vitro including formaldehyde, acrolein, malondialdehyde, and 4-HNE (MacKenzie 2009; Matveychuk 2015; Fig. 6).

Song et al. (2010) conducted a comprehensive study on the effects of PLZ on formaldehyde-induced toxicity to primary cortical neurons and cortical astrocytes in vitro. Formaldehyde inhibited glutamate uptake by decreasing expression of glutamate transporters in astrocytes and activated the second messenger $\mathrm{p} 38$ mitogen-activated protein kinase (p38 MAPK), which participates in a signaling cascade modulating cellular responses to cytokines and stress, and these effects were attenuated by PLZ. In neurons, formaldehyde activated p38MAPK and decreased activation of AKT (a

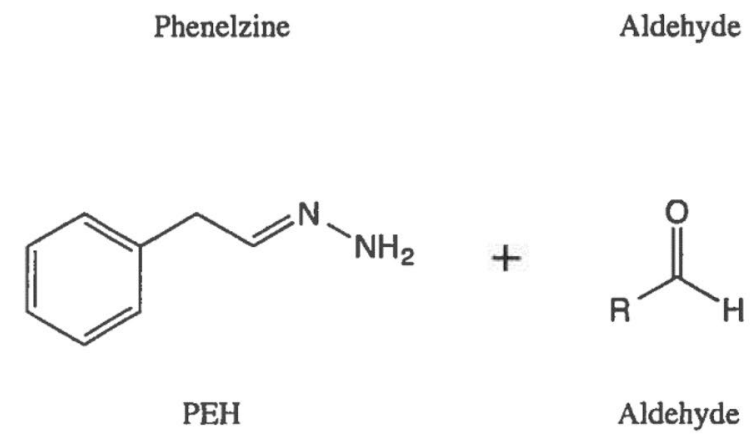

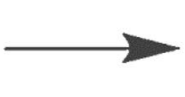<smiles>P/C=N/NCCc1ccccc1</smiles><smiles>CC=N/N=C/Cc1ccccc1</smiles>

Fig. 4 General scheme for reaction of PLZ and PEH with aldehydes 


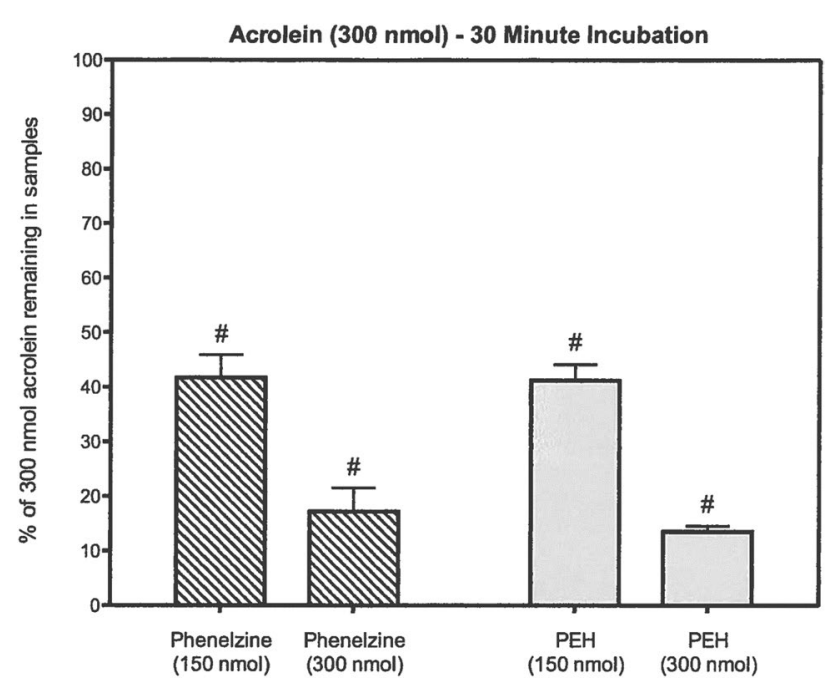

Fig. 6 Reduction of acrolein levels in vitro by PLZ and PEH (from Matveychuk 2015, with permission). Acrolein and PLZ or PEH were incubated in phosphate-buffered saline, $\mathrm{pH} 7.4$, for $30 \mathrm{~min}$. Following incubation, $200 \mu \mathrm{l}$ samples were adjusted to $\mathrm{pH} 4$ and $50 \mu \mathrm{l}$ of $O$-(2,3,4,5,6-pentafluorobenzyl)-hydroxylamine $\mathrm{HCl}$ was added to give a concentration of $20 \mathrm{mM}$. After $60 \mathrm{~min}$ of incubation at room temperature, the samples were acidified and the derivatized aldehyde was extracted with $300 \mu \mathrm{l}$ hexane. A portion of the hexane layer was used for GC-MS analysis. Data are normalized relative to controls and represent means \pm SEM $(N=5)$. All values significantly differ from controls

marker of neuronal survival), and PLZ reversed these effects (Song et al. 2010). PLZ has also been reported to attenuate 4-HNE-induced mitochondrial dysfunction in a rat model of traumatic brain injury (Singh et al. 2013) and to mitigate 4-HNE-induced damage to proteins and lipids in blood plasma (Mustafa et al. 2018b).

\section{Inhibition of Primary Amine Oxidase (PrAO) by PLZ and PEH}

PrAO is a copper-containing transmembrane glycoprotein, and the extracellular domain may be cleaved off, resulting in a circulating form in plasma (Shanahan et al. 2019; Stolen et al. 2004). In some tissues, the membrane form is synonymous with Vascular Adhesion Protein (VAP-1) involved in migration of leukocytes at sites of inflammation (Pannecoeck et al. 2015; Salmi and Jalkanen 2001; Shanahan et al. 2019). The aldehydes formaldehyde and methylglyoxal are formed by deamination of methylamine and aminoacetone catalyzed, respectively, by the circulating plasma form and the membrane-associated form of PrAO (Lyles 1996; Shanahan et al. 2019). These aldehydes have been shown to increase the formation of $\beta$-amyloid (A $\beta$ ) $\beta$-sheets and fibrillogenesis (Chen et al. 2006), both of which are proposed to be major contributing factors to

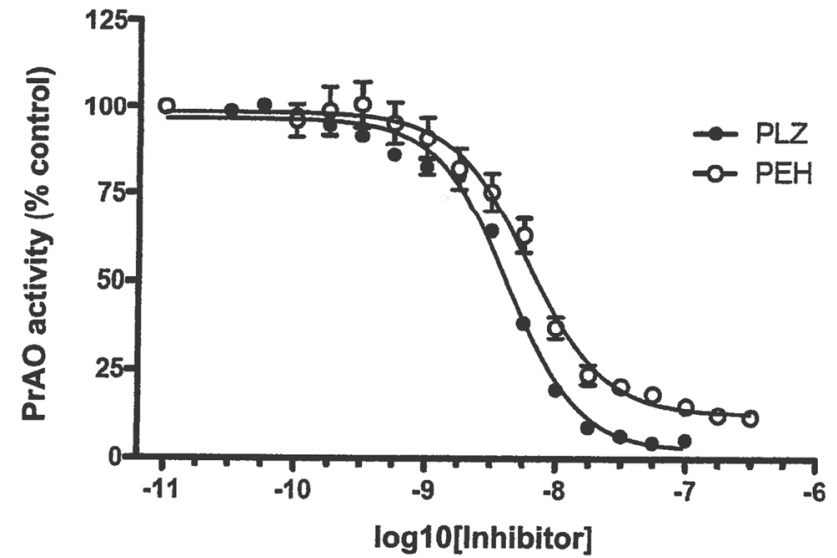

Fig. 7 Inhibition by PLZ and PEH of PrAO from a human source (from MacKenzie 2009, with permission). A. Holt (University of Alberta) purified soluble human PrAO from $\mathrm{CHO}$ cells overexpressing the human enzyme. PrAO activity was measured using a modification of the spectrophotometric assay of Holt and Palcic (2006), with methylamine as the substrate for the enzyme. Values are expressed as \% of control PrAO activity (means \pm SEM, $N=3$ )

the pathology of AD (Selkoe 2001; Tanzi and Bertram 2005). Increased serum PrAO activity has been reported in AD patients (Chen et al. 2006; del Mar et al. 2005; Ferrer et al. 2002; Gubisne-Haberle et al. 2004; Pannecoeck et al. 2015; Unzeta et al. 2007; Valente et al. 2012; Yu et al. 2003), and Jiang et al. (2008) reported a strong expression of PrAO colocalized with $A \beta$ deposits on blood vessels of postmortem brain samples from AD patients. Elevated PrAO plasma levels have also been reported in patients with active relapsing multiple sclerosis (Airas et al. 2008), diabetes, and inflammation (Pannecoeck et al. 2015), and inhibition of PrAO has been reported to be of benefit in the relapsing experimental autoimmune encephalomyelitis (EAE) animal model of multiple sclerosis (O'Rourke et al. 2007) and to have anti-inflammatory actions that are beneficial to vascular health (Jarnicki et al. 2016). Ischemia-reperfusion injury in a mouse model of stroke is attenuated in PrAO-deficient mice and by PrAO inhibitors (Kiss et al. 2008). Additionally, inhibition of PrAO has been reported to provide anti-inflammatory protection in a mouse model of intracerebral hemorrhagic stroke (Ma et al. 2011). Horváth et al. (2017) reported that an inhibitor of PrAO had analgesic and anti-inflammatory effects in a mouse model of chronic arthritis. It is of interest that PLZ has also been shown to be a strong inhibitor of PrAO (Lizcano et al. 1996; Lyles 1996); it has been demonstrated in our group that PEH is also a potent inhibitor in vitro of PrAO from human sources (MacKenzie 2009; Fig. 7) and that ip injection of PLZ or PEH increases rat brain levels of methylamine, an indirect indicator of reduction of formaldehyde levels (Matveychuk et al. 2013). These findings and the observations regarding the other actions of PEH 
mentioned above in this review paper suggest that studies on the effects of PLZ and PEH on animal models of AD are warranted.

\section{Other Potential Applications of PLZ Based on Neuroprotection}

\section{PLZ and Traumatic Brain Injury and Spinal Cord Injury}

Traumatic brain injury (TBI) has been reported to result in mitochondrial dysfunction and induction of lipid peroxidation, the latter resulting in production of reactive aldehydes such as acrolein and 4-HNE, which probably accumulate because of their reduced clearance from damaged neurons (Hill et al. 2017, 2018, 2019). Singh et al. (2013) found that pretreatment with PLZ reduced the inhibitory effects of 4-HNE on mitochondrial complex I and II respiration and also produced a reduction of 4-HNE levels in mitochondria. They also found that PLZ administered to rats $15 \mathrm{~min}$ after controlled cortical impact-TBI (CCI-TBI) prevented the decrease in respiratory control ratio produced by the CCITBI. Further, they reported that PLZ increased the amount of spared cortical tissue from 86 to $97 \%$ and concluded that the neuroprotective actions of PLZ were the result of protection of mitochondria by scavenging 4-HNE. PLZ pretreatment has been reported by Cebak et al. (2017) to prevent both mitochondrial dysfunction and oxidative modification of mitochondrial proteins produced in isolated non-injured rat brain cortical mitochondria by 4-HNE or acrolein. Pargyline, an MAOI which does not have a hydrazine moiety, had no protective effects in a similar study, and the authors concluded that the response to PLZ was related to carbonyl scavenging rather than to inhibition of MAO (Cebak et al. 2017). In a parallel in vivo study, these researchers found that PLZ given 15 min after the CCI-TBI resulted in a reduction of mitochondrial respiratory dysfunction and an increase in cortical tissue sparing.

Kulbe et al. (2018) examined the effects of continuous infusion (for $72 \mathrm{~h}$ ) of PLZ following severe CCI-TBI in rats and found that it attenuated mitochondrial levels of 4-HNE and acrolein and maintained the mitochondrial respiratory control ratio and cytoskeletal integrity. In a recent study, Hill et al. (2020) reported that administration of PLZ to young adult male rats after severe CCI-TBI resulted in a preservation of both synaptic and non-synaptic mitochondrial bioenergetics observed $24 \mathrm{~h}$ later, and that the protection was partially maintained at $72 \mathrm{~h}$.

Acrolein has been proposed to be involved in the propagation of neuropathic pain in spinal cord injury (SCI) by activation of the transient receptor potential ankyrin 1 (TRPA1) cation channel. Lin et al. (2018) reported that PLZ improved
post-SCI hypersensitivity and motor neuron survival, decreased acrolein levels and suppressed TRPA1 upregulation in a rat model of ischemia-reperfusion SCI. PLZ has also been reported to reduce the hyperalgesic effects of acrolein inhalation in a rat model of contusion SCI (Butler et al. 2017). Chen et al. (2016b) found reduced neuropathic pain after injury in a rat model of SCI when PLZ was administered by acute, delayed and chronic dosage schedules. It is relevant that hydralazine, another hydrazine drug that, like PLZ, scavenges acrolein, also reduces neuropathic pain and provides neuroprotection in SCI (Due et al. 2014; Liu-Snyder et al. 2006; Park et al. 2015). Chen et al. (2016b) found that PLZ and hydralazine each produced a dose-dependent reduction in levels of acrolein in vivo and that PLZ facilitated recovery of locomotor function and neuroprotection of spinal cord tissue when given for 2 weeks after injury.

\section{PLZ and Multiple Sclerosis}

As mentioned previously in this review, in relapsing multiple sclerosis elevated PrAO activity has been observed in patients (Airas et al. 2008), and improvement of symptoms has been reported in the EAE model after inhibition of PrAO (O'Rourke et al. 2007). Accumulation of toxic aldehydes in plasma, CSF and brain tissue from multiple sclerosis patients has been reported (Bizzozero et al. 2005; Calabrese et al. 1994; Hunter et al. 1985). Studies on the possible role of acrolein in multiple sclerosis have received considerable interest in more recent years (Leung et al. 2011; Tully et al. 2018). Acrolein induces damage to myelin in the spinal cord of mammals (Shi et al. 2011, 2015), and there have been reports of elevated levels of acrolein in the EAE mouse model of multiple sclerosis (Leung et al. 2011; Tully et al. 2018). Hydralazine, which like PLZ is a carbonyl scavenger, has been reported to improve symptoms (Leung et al. 2011) and reduce spinal cord levels of acrolein in the EAE model (Tully et al. 2018). In studies on chronic administration of PLZ in this same model, Musgrave et al. (2011) found that daily injection of PLZ to female mice with EAE prior to onset of clinical signs delayed onset and severity of symptoms and resulted in enhanced exploratory activity, improved depression-like symptoms and a normalization of levels of 5-HT in the ventral horn of the spinal cord. The same research group later found that PLZ administration to the EAE mice even after the onset of clinical signs can reduce the severity of these signs and improve exploratory activity (Benson et al. 2013). Potter et al. (2016) found an antinociceptive effect and normalization of primary somatosensory cortex neural ensemble responses, neuronal morphology and cortical microglia numbers as well as attenuation of reactivity of the VGLUT1 glutamate transporter in EAE mice treated with PLZ. Antinociceptive effects have also been studied in models other than EAE. Mifflin et al. (2016) studied the effects of PLZ and PEH in the formalin model of tonic nociception and found 
that both PEH and PLZ reduced nociceptive behaviors in the second phase of pain induction; interestingly, the reduction was similar in both sexes of mice in the case of PEH, but much more prominent in male mice in the case of PLZ. Potter et al. (2018) found that PLZ selectively inhibits ongoing inflammatory pain but spares transient reflexive and acute nociception; these same researchers reported that PLZ reduced intracellular calcium responses to superfusion of glutamate ex vivo in lumbar spinal cord slices. As mentioned earlier in this review paper, PLZ has been reported to reduce pain in TBI and SCI, and sequestration of acrolein is thought to play a role in that action of PLZ. Similar effects of PEH and PLZ on acrolein in multiple sclerosis are certainly feasible, but, to our knowledge, this possibility has not been studied to date. Similarly, we are not aware of any direct comparisons of long-term administration of PLZ and PEH in animal models of multiple sclerosis. Such studies are warranted in this and other animal models of neurodegenerative disorders to determine whether the GABA levels gradually decrease over time in response to PLZ since less PEH may be formed as PLZ-induced inhibition of MAO increases, oxidation of PLZ to PEH decreases, and inhibition of GABA-T is consequently reduced.

\section{PEH as an Anticonvulsant?}

To our knowledge, PEH has not been tested as an anticonvulsant in vivo in animal models, but the literature on PEH suggests that such studies are warranted. In a physiological study, Duffy et al. (2004) applied solutions of PEH to rat hippocampal slices and found a $60 \%$ increase in GABA levels in the slices. Further, they observed that hyper-excitation during epileptiform bursting induced by superfusion with $\mathrm{Mg}^{2+}$-free or high- $\mathrm{K}^{+}$artificial CSF was reduced, results suggesting a potential anticonvulsant action of PEH. The GABA-T-inhibiting/GABA-elevating action of PEH in rat brain ex vivo also suggests that $\mathrm{PEH}$ should be investigated as a potential anticonvulsant. Vigabatrin is a GABA-T inhibitor marketed as an anticonvulsant, but studies in rats ex vivo indicated that both PLZ and PEH are much more potent than vigabatrin at inhibiting GABA-T and elevating brain GABA levels in rats (MacKenzie et al. 2008a; Todd and Baker 2008). In addition, PLZ and PEH can sequester reactive aldehydes such as malondialdehyde, acrolein and 4-HNE that have been implicated in the etiology of some types of epilepsy (Cardenas-Rodriguez et al. 2013; Hogard et al. 2017; Lorigados Pedre et al. 2018; Olowe et al. 2020).
Other Neurobiological Findings with PLZ that may Have Relevance to Neuroprotection

The reactive nitrogen species (RNS) peroxynitrite is produced by the fusion of the superoxide anion and nitric oxide. Peroxynitrite is thought to produce its adverse effects after decomposing to yield a nitrogen dioxide radical, a hydroxyl radical and a nitryl cation, all of which can cause damage to nerve cells (Bedard and Krause 2007; Mustafa et al. 2018a). Peroxynitrite has been linked to the etiology of disorders such as diabetes, hypertension and atherosclerosis and may contribute to aging (Finkel and Holbrook 2000; Niemann et al. 2017; Sugamura and Keaney 2011). Mustafa et al. (2018a) reported that PLZ protected against protein carbonyl formation, protein nitration and lipid peroxidation in peroxynitrite-treated plasma and platelet samples. The authors concluded that the ability of PLZ to scavenge reactive aldehydes was responsible for its protective effects in all three of these oxidative stress situations (Mustafa et al. 2018a).

The dopamine system neurotoxin 1-methyl-4-phenyl1,2,3,6-tetrahydropyridine (MPTP) is converted metabolically to its metabolite 1-methyl-4-phenylpyridinium $\left(\mathrm{MPP}^{+}\right)$ by MAO-B, and this metabolite has been proposed to cause cell death by opening the mitochondrial permeability transition pore (Cassarino et al. 1999; Lee et al. 2003). Lee et al. (2003) studied the effects of $\mathrm{MPP}^{+}$on differentiated PC12 cells and reported that PLZ reduced $\mathrm{MMP}^{+}$-induced condensation and fragmentation of nuclei and also counteracted the decrease in mitochondrial membrane potential, as well as cytochrome c release, formation of reactive oxygen species, depletion of total glutathione levels, and cell death induced by $\mathrm{H}_{2} \mathrm{O}_{2}$

Actions of PLZ on brain-derived neurotrophic factor (BDNF) may also contribute to the neuroprotective properties of PLZ. Chronic, but not acute, administration of a number of antidepressants, including PLZ, has been reported to produce an increase in rat brain levels of BDNF (Balu et al. 2008; Nibuya et al. 1995). In a study in rats, Dwivedi et al. (2006) reported that chronic (21 days) administration of PLZ resulted in increased mRNA expression of BDNF in frontal cortex and hippocampus and reversed the corticosterone-induced decrease in the expression of BDNF in the same brain areas. In a study on mouse hippocampus, Fred et al. (2019) investigated the effects of ip injection of the antidepressants PLZ, fluoxetine, imipramine and ketamine on the coupling of the tropomyosin-related kinase $\mathrm{B}$ (TRKB) receptor and the adaptor protein complex-2 (AP2 ) involved in vesicular endocytosis and suggested a novel mechanism for all of these antidepressants in which they disrupt the TRKB:AP2M subunit interaction and thereby promote TRKB cell surface exposure and BDNF signaling. 
The neural cell adhesion molecule L1CAM (L1) plays a functional role in the developing and adult nervous system and is thought to be linked to several neurodegenerative diseases (Joseph et al. 2020). In the injured spinal cord, L1 can promote axonal regrowth and enhance survival of neurons, synaptic plasticity and remyelination ( $\mathrm{Li}$ et al. 2018). In studies in a zebrafish SCI model, Li et al. (2018) found that addition of PLZ to the aquarium water resulted in an accelerated recovery of the reduced locomotor activity produced by the spinal cord transection and promoted axonal regrowth and remyelination in both larval and adult zebrafish. In the same study, these researchers proposed that PLZ was a L1 mimetic since it upregulated expression and proteolysis of $\mathrm{L} 1$ and phosphorylation of extracellular-signal-regulated-kinase (Erk) caudal to the site of the lesion in the spinal cord. In another study in zebrafish, Joseph et al. (2020) reported that PLZ counteracted the toxicity induced by the environmental neurotoxin paraquat - they found that PLZ prevented the reduction in tyrosine hydroxylase activity and dopamine levels, reduced generation of reactive oxygen species, protected against impairment of mitochondrial viability, enhanced the antioxidant system and prevented a decrease in levels of adenosine triphosphate (ATP).

Phosphorylation of Fas-associated death domain (FADD), an adaptor of death receptors, can result in induction of antiapoptotic actions (García-Fuster and García-Sevilla 2016). It has been reported that acute administration of PLZ to rats resulted in a marked increase in the ratio of phosphorylated to non-phosphorylated FADD in brain cortex, and the authors suggested that this potential anti-apoptotic action of PLZ may be related to its GABA-elevating action and subsequent activation of $\mathrm{GABA}_{\mathrm{A}}$ receptors. However, the effect on the p-FADD/ FADD ratio was not evident after chronic administration (14 days) of PLZ, perhaps because MAO-mediated generation of PEH from PLZ cannot be maintained under conditions of substantial MAO inhibition.

In metabolomics studies, we also found that ip treatment of male rats with PLZ or PEH resulted in marked increases in brain cortex levels of ornithine (MacKenzie et al. 2008b) and a number of $\mathrm{N}$-acetylated amino acids (Wood et al. 2020). We speculated that the increased ornithine levels may be an indicator of decreased formation of glutamate and/or polyamines (resulting in decreased formation of reactive aldehydes such as acrolein and 3-AP), thus contributing to neuroprotection. The possible involvement of the effects on $N$-acetylamino acids in neuroprotection awaits a further knowledge of the role of these $N$-acetylamino acids in the central nervous system, although $N$-acetylasparate is present in millimolar concentrations in brain and is a marker for viable neurons (Demougeot et al. 2001), $N$-acetylglutamate is a modulator of the urea cycle, $N$-acetyl-leucine is a modulator of vestibulocerebellar and posterolateral thalamic circuits related to vestibular function (Günther et al. 2015) and $N$-acetylglutamine has been proposed to be involved in the sleep-wake cycle (Bourdon et al. 2018).

\section{Conclusion}

Although marketed initially as an antidepressant because of its ability to inhibit MAO, PLZ is a multifaceted drug with a multitude of actions that may be relevant to neuroprotection and the pharmacotherapy of several psychiatric and neurological disorders. Its anxiolytic effects have been demonstrated clinically, and results from animal models suggest that PLZ and/or its metabolite PEH could be considered for studies as adjunctive agents in disorders such as stroke, AD, PD, SCI, TBI, epilepsy, and multiple sclerosis. PLZ and PEH share abilities to inhibit GABA-T and PrAO and sequester reactive aldehydes. They differ from each other in their ability to inhibit MAO, with PLZ being a very strong irreversible of MAO-A and $-\mathrm{B}$, while $\mathrm{PEH}$ is only a weak inhibitor of both of these isoforms of MAO.

This difference in inhibition of MAO suggests that PEH is unlikely to have antidepressant efficacy, but that it is worth investigating in some of the other disorders mentioned above because of its other neuroprotective properties and the fact that the dietary caution recommended with non-selective, irreversible MAOIs would not be required.

Acknowledgements The authors are grateful for funding provided by the Canadian Institutes of Health Research (CIHR) and the Department of Psychiatry, Faculty of Medicine and Dentistry and the Offices of the Vice-President Research and Provost at the University of Alberta. The expert technical and administrative help of Gail Rauw, Trudy Valliere, Tricia Kent, and Dr. James Wong are gratefully acknowledged. The synthetic support of Dr. Amin Khan and Dr. Carlos Velazquez was also much appreciated.

Author Contributions All authors contributed to sections of the manuscript dealing with their areas of focus. GBB did the initial literature search and prepared the initial draft of the paper. All authors contributed to the editing of that draft.

Funding The authors are grateful for funding from CIHR (MOP86712, Phenylalkylhydrazine Drugs and Neuroprotection, GBB and KGT) and the University of Alberta. GBB held a TRIP Research Allowance from the Faculty of Medicine and Dentistry. DM held a CIHR Doctoral Research Award.

Data Availability This a review article, but statements are based on the authors' research. Data can be obtained from the authors on reasonable request.

\section{Declarations}

Conflict of interest GBB has had informal discussions about phenelzine with NeuraWell Therapeutics, but the company has had no input into this manuscript. EMM now works for Lundbeck Canada, but the company has had no input into this manuscript. The authors have no other conflicts of interest to declare. 
Open Access This article is licensed under a Creative Commons Attribution 4.0 International License, which permits use, sharing, adaptation, distribution and reproduction in any medium or format, as long as you give appropriate credit to the original author(s) and the source, provide a link to the Creative Commons licence, and indicate if changes were made. The images or other third party material in this article are included in the article's Creative Commons licence, unless indicated otherwise in a credit line to the material. If material is not included in the article's Creative Commons licence and your intended use is not permitted by statutory regulation or exceeds the permitted use, you will need to obtain permission directly from the copyright holder. To view a copy of this licence, visit http://creativecommons.org/licenses/by/4.0/.

\section{References}

Aarre TF (2003) Phenelzine efficacy in refractory social anxiety disorder: a case series. Nord J Psychiatry 57:313-315. https://doi. org/10.1080/08039480310002110

Adolfsson R, Gottfries C, Oreland L, Wiberg A, Winblad B (1980) Increased activity of brain and platelet monoamine oxidase in dementia of Alzheimer type. Life Sci 27:1029-1034

Agostinelli E, Tempera G, Viceconte N et al (2010) Potential anticancer application of polyamine oxidation products formed by amine oxidase: a new therapeutic approach. Amino Acids 38:353-368. https://doi.org/10.1007/s00726-009-0431-8

Airas L, Lindsberg PJ, Karjalainen-Lindsberg ML, Mononen I, Kotisaari K, Smith DJ, Jalkanen S (2008) Vascular adhesion protein-1 in human ischaemic stroke. Neuropathol Appl Neurobiol 34:394-402. https://doi.org/10.1111/j.1365-2990.2007.00911.x

Al-Nuaimi SK, MacKenzie EM, Baker GB (2012) Monoamine oxidase inhibitors and neuroprotection: a review. Am J Ther 19:436-448

Baillet A, Chanteperdrix V, Trocmé C, Casez P, Garrel C, Besson G (2010) The role of oxidative stress in amyotrophic lateral sclerosis and Parkinson's disease. Neurochem Res 35:1530-1537. https://doi.org/10.1007/s11064-010-0212-5

Baker G, Matveychuk D, MacKenzie EM, Holt A, Wang Y, Kar S (2019) Attenuation of the effects of oxidative stress by the MAOinhibiting antidepressant and carbonyl scavenger phenelzine. Chem Biol Interact 304:139-147. https://doi.org/10.1016/j.cbi. 2019.03.003

Baker GB, Dewhurst WG (1985) Biochemical theories of affective disorders. In: Dewhurst WG, Baker GB (eds) Pharmacotherapy of affective disorders: theory and practice. Croom Helm, London, pp 1-60

Baker GB, Matveychuk D, MacKenzie EM, Dursun SM, Mousseau DD (2012) Monoamine oxidase inhibitors and neuroprotective mechanisms. Bull Clin Psychopharmacol 22:293-296

Baker GB, Wong JT, Yeung JM, Coutts RT (1991) Effects of the antidepressant phenelzine on brain levels of gamma-aminobutyric acid (GABA). J Affect Disord 21:207-211

Balu DT, Hoshaw BA, Malberg JE, Rosenzweig-Lipson S, Schechter LE, Lucki I (2008) Differential regulation of central BDNF protein levels by antidepressant and non-antidepressant drug treatments. Brain Res 1211:37-43

Beach TG, Walker R, McGeer EG (1989) Patterns of gliosis in Alzheimer's disease and aging cerebrum. Glia 2:420-436. https://doi. org/10.1002/glia.440020605

Bedard K, Krause KH (2007) The NOX family of ROS-generating NADPH oxidases: physiology and pathophysiology. Physiol Rev 87:245-313. https://doi.org/10.1152/physrev.00044.2005

Benson CA, Wong G, Tenorio G, Baker GB, Kerr BJ (2013) The MAO inhibitor phenelzine can improve functional outcomes in mice with established clinical signs in experimental autoimmune encephalomyelitis (EAE). Behav Brain Res 252:302-311. https:// doi.org/10.1016/j.bbr.2013.06.019

Bizzozero OA, DeJesus G, Callahan K, Pastuszyn A (2005) Elevated protein carbonylation in the brain white matter and gray matter of patients with multiple sclerosis. J Neurosci Res 81:687-695. https://doi.org/10.1002/jnr.20587

Blier P (2016) Neurobiology of depression and mechanism of action of depression treatments. J Clin Psychiatry 77:e319. https://doi. org/10.4088/JCP.13097tx3c

Bourdon AK, Spano GM, Marshall W et al (2018) Metabolomic analysis of mouse prefrontal cortex reveals upregulated analytes during wakefulness compared to sleep. Sci Rep 8:11225. https://doi. org/10.1038/s41598-018-29511-6

Bradley MA, Markesbery WR, Lovell MA (2010) Increased levels of 4-hydroxynonenal and acrolein in the brain in preclinical Alzheimer disease. Free Radic Biol Med 48:1570-1576. https://doi org/10.1016/j.freeradbiomed.2010.02.016

Buckley PF (2019) Neuroinflammation and schizophrenia. Curr Psychiatry Rep 21:72. https://doi.org/10.1007/s11920-019-1050-Z

Buigues J, Vallejo J (1987) Therapeutic response to phenelzine in patients with panic disorder and agoraphobia with panic attacks. J Clin Psychiatry 48:55-59

Burke WJ, Li SW, Chung HD et al (2004) Neurotoxicity of MAO metabolites of catecholamine neurotransmitters: role in neurodegenerative diseases. Neurotoxicology 25:101-115. https://doi. org/10.1016/s0161-813x(03)00090-1

Burke WJ, Li SW, Williams EA, Nonneman R, Zahm DS (2003) 3,4-Dihydroxyphenylacetaldehyde is the toxic dopamine metabolite in vivo: implications for Parkinson's disease pathogenesis. Brain Res 989:205-213

Butler B, Acosta G, Shi R (2017) Exogenous acrolein intensifies sensory hypersensitivity after spinal cord injury in rat. J Neurol Sci 379:29-35. https://doi.org/10.1016/j.jns.2017.05.039

Cagle BS, Crawford RA, Doorn JA (2019) Biogenic aldehyde-mediated mechanisms of toxicity in neurodegenerative disease. Curr Opin Toxicol 13:16-21. https://doi.org/10.1016/j.cotox.2018.12.002

Cai Z (2014) Monoamine oxidase inhibitors: promising therapeutic agents for Alzheimer's disease (Review). Mol Med Rep 9:15331541. https://doi.org/10.3892/mmr.2014.2040

Calabrese V, Raffaele R, Cosentine E, Rizza V (1994) Changes in cerebrospinal fluid levels of malondialdehyde and glutathione reductase activity in multiple sclerosis. Int J Clin Pharmacol Res 14:119-123

Cardenas-Rodriguez N, Huerta-Gertrudis B, Rivera-Espinosa L, Montesinos-Correa H, Bandala C, Carmona-Aparicio L, CoballaseUrrutia E (2013) Role of oxidative stress in refractory epilepsy: evidence in patients and experimental models. Int $\mathrm{J}$ Mol Sci 14:1455-1476. https://doi.org/10.3390/ijms14011455

Casado A, Encarnacion Lopez-Fernandez M, Concepcion Casado M, de La Torre R (2008) Lipid peroxidation and antioxidant enzyme activities in vascular and Alzheimer dementias. Neurochem Res 33:450-458. https://doi.org/10.1007/s11064-007-9453-3

Cassarino DS, Parks JK, Parker WD Jr, Bennett JP Jr (1999) The parkinsonian neurotoxin $\mathrm{MPP}^{+}$opens the mitochondrial permeability transition pore and releases cytochrome $c$ in isolated mitochondria via an oxidative mechanism. Biochim Biophys Acta 1453:49-62

Cebak JE, Singh IN, Hill RL, Wang JA, Hall ED (2017) Phenelzine protects brain mitochondrial function in vitro and in vivo following traumatic brain injury by scavenging the reactive carbonyls 4-hydroxynonenal and acrolein leading to cortical histological neuroprotection. J Neurotrauma 34:1302-1317. https://doi.org/ 10.1089/neu.2016.4624

Chen AT, Nasrallah HA (2019) Neuroprotective effects of the second generation antipsychotics. Schizophr Res 208:1-7. https://doi. org/10.1016/j.schres.2019.04.009 
Chen CH, Joshi AU, Mochly-Rosen D (2016a) The role of mitochondrial aldehyde dehydrogenase 2 (ALDH2) in neuropathology and neurodegeneration. Acta Neurol Taiwanica 25(4):111-123

Chen CM, Liu JL, Wu YR, Chen YC, Cheng HS, Cheng ML, Chiu DT (2009) Increased oxidative damage in peripheral blood correlates with severity of Parkinson's disease. Neurobiol Dis 33:429-435. https://doi.org/10.1016/j.nbd.2008.11.011

Chen K, Maley J, Yu PH (2006) Potential implications of endogenous aldehydes in beta-amyloid misfolding, oligomerization and fibrillogenesis. J Neurochem 99:1413-1424

Chen Xu W, Yi Y, Qiu L, Shuaib A (2000) Neuroprotective activity of tiagabine in a focal embolic model of cerebral ischemia. Brain Res 874:75-77. https://doi.org/10.1016/s0006-8993(00)02554-3

Chen Z, Park J, Butler B et al (2016b) Mitigation of sensory and motor deficits by acrolein scavenger phenelzine in a rat model of spinal cord contusive injury. J Neurochem 138:328-338. https://doi.org/ 10.1111/jnc. 13639

Clineschmidt BV, Horita A (1969a) The monoamine oxidase catalyzed degradation of phenelzine-1-14C, an irreversible inhibitor of monoamine oxidase- - I. Studies in vitro. Biochem Pharmacol 18:1011-1020

Clineschmidt BV, Horita A (1969b) The monoamine oxidase catalyzed degradation of phenelzine-1-14C, an irreversible inhibitor of monoamine oxidase-II. Studies in vivo. Biochem Pharmacol 18:1021-1028

Cohen SM, Tsien RW, Goff DC, Halassa MM (2015) The impact of NMDA receptor hypofunction on GABAergic neurons in the pathophysiology of schizophrenia. Schizophr Res 167:98-107. https://doi.org/10.1016/j.schres.2014.12.026

Dalfo E, Ferrer I (2008) Early alpha-synuclein lipoxidation in neocortex in Lewy body diseases. Neurobiol Aging 29:408-417. https:// doi.org/10.1016/j.neurobiolaging.2006.10.022

Dalfo E, Portero-Otin M, Ayala V, Martinez A, Pamplona R, Ferrer I (2005) Evidence of oxidative stress in the neocortex in incidental Lewy body disease. J Neuropathol Exp Neurol 64:816-830

Dang TN, Arseneault M, Murthy V, Ramassamy C (2010) Potential role of acrolein in neurodegeneration and in Alzheimer's disease. Curr Mol Pharmacol 3:66-78

Davidson J, Raft D, Pelton S (1987) An outpatient evaluation of phenelzine and imipramine. J Clin Psychiatry 48:143-146

del Mar HM, Esteban M, Szabo P, Boada M, Unzeta M (2005) Human plasma semicarbazide sensitive amine oxidase (SSAO), betaamyloid protein and aging. Neurosci Lett 384:183-187

Demougeot C, Garnier P, Mossiat C, Bertrand N, Giroud M, Beley A, Marie C (2001) $N$-acetylaspartate, a marker of both cellular dysfunction and neuronal loss: its relevance to studies of acute brain injury. J Neurochem 77:408-415. https://doi.org/10.1046/j. 1471-4159.2001.00285.x

Dexter DT, Carter CJ, Wells FR, Agid Y, Lees A, Jenner P, Marsden CD (1989) Basal lipid peroxidation in substantia nigra is increased in Parkinson's disease. J Neurochem 52:381-389

Due MR, Park J, Zheng L, Walls M, Allette YM, White FA, Shi R (2014) Acrolein involvement in sensory and behavioral hypersensitivity following spinal cord injury in the rat. J Neurochem 128:776-786. https://doi.org/10.1111/jnc. 12500

Duffy S, Nguyen PV, Baker GB (2004) Phenylethylidenehydrazine, a novel GABA-transaminase inhibitor, reduces epileptiform activity in rat hippocampal slices. Neuroscience 126:423-432. https:// doi.org/10.1016/j.neuroscience.2004.03.007

Dwivedi Y, Rizavi HS, Pandey GN (2006) Antidepressants reverse corticosterone-mediated decrease in brain-derived neurotrophic factor expression: differential regulation of specific exons by antidepressants and corticosterone. Neuroscience 139:1017-1029

Eisenhofer G, Kopin IJ, Goldstein DS (2004) Catecholamine metabolism: a contemporary view with implications for physiology and medicine. Pharmacol Rev 56:331-349. https://doi.org/10.1124/ pr.56.3.1

Esterbauer H, Schaur RJ, Zollner H (1991) Chemistry and biochemistry of 4-hydroxynonenal, malondialdehyde and related aldehydes. Free Radic Biol Med 11:81-128

Ferrer I, Lizcano JM, Hernandez M, Unzeta M (2002) Overexpression of semicarbazide sensitive amine oxidase in the cerebral blood vessels in patients with Alzheimer's disease and cerebral autosomal dominant arteriopathy with subcortical infarcts and leukoencephalopathy. Neurosci Lett 321:21-24

Finkel T, Holbrook NJ (2000) Oxidants, oxidative stress and the biology of ageing. Nature 408:239-247. https://doi.org/10.1038/ 35041687

Foerster BR, Pomper MG, Callaghan BC et al (2013) An imbalance between excitatory and inhibitory neurotransmitters in amyotrophic lateral sclerosis revealed by use of 3-T proton magnetic resonance spectroscopy. JAMA Neurol 70:1009-1016. https:// doi.org/10.1001/jamaneurol.2013.234

Fowler JS, Logan J, Volkow ND, Wang GJ, MacGregor RR, Ding YS (2002) Monoamine oxidase: radiotracer development and human studies. Methods 27:263-277

Fowler JS, Volkow ND, Wang GJ, Logan J, Pappas N, Shea C, MacGregor R (1997) Age-related increases in brain monoamine oxidase B in living healthy human subjects. Neurobiol Aging $18: 431-435$

Fred SM, Laukkanen L, Brunello CA et al (2019) Pharmacologically diverse antidepressants facilitate TRKB receptor activation by disrupting its interaction with the endocytic adaptor complex AP-2. J Biol Chem 294:18150-18161. https://doi.org/10.1074/ jbc.RA119.008837

García-Fuster MJ, García-Sevilla JA (2016) Effects of anti-depressant treatments on FADD and p-FADD protein in rat brain cortex: enhanced anti-apoptotic p-FADD/FADD ratio after chronic desipramine and fluoxetine administration. Psychopharmacology 233:2955-2971. https://doi.org/10.1007/s00213-016-4342-6

Gerlach M, Youdim MB, Riederer P (1996) Pharmacology of selegiline. Neurology 47:S137-145

Gillman PK (2018) A reassessment of the safety profile of monoamine oxidase inhibitors: elucidating tired old tyramine myths. J Neural Transm 125:1707-1717. https://doi.org/10.1007/ s00702-018-1932-y

Gomez-Ramos A, Diaz-Nido J, Smith MA, Perry G, Avila J (2003) Effect of the lipid peroxidation product acrolein on tau phosphorylation in neural cells. J Neurosci Res 71:863-870. https://doi. org/10.1002/jnr. 10525

Green AR, Hainsworth AH, Jackson DM (2000) GABA potentiation: a logical pharmacological approach for the treatment of acute ischaemic stroke. Neuropharmacology 39:1483-1494

Greilberger J, Koidl C, Greilberger M et al (2008) Malondialdehyde, carbonyl proteins and albumin-disulphide as useful oxidative markers in mild cognitive impairment and Alzheimer's disease. Free Radic Res 42:633-638. https://doi.org/10.1080/1071576080 2255764

Grünblatt E, Mandel S, Jacob-Hirsch J et al (2004) Gene expression profiling of Parkinsonian substantia nigra pars compacta; alterations in ubiquitin-proteasome, heat shock protein, iron and oxidative stress regulated proteins, cell adhesion/cellular matrix and vesicle trafficking genes. J Neural Transm 111:1543-1573. https://doi.org/10.1007/s00702-004-0212-1

Gubisne-Haberle D, Hill W, Kazachkov M, Richardson JS, Yu PH (2004) Protein cross-linkage induced by formaldehyde derived from semicarbazide-sensitive amine oxidase-mediated deamination of methylamine. J Pharmacol Exp Ther 310:1125-1132. https://doi.org/10.1124/jpet.104.068601

Günther L, Beck R, Xiong G et al (2015) N-acetyl-L-leucine accelerates vestibular compensation after unilateral labyrinthectomy by 
action in the cerebellum and thalamus. PLoS ONE 10:e0120891. https://doi.org/10.1371/journal.pone.0120891

Gustaw-Rothenberg K, Kowalczuk K, Stryjecka-Zimmer M (2010) Lipid peroxidation markers in Alzheimer's disease and vascular dementia. Geriatr Gerontol Int 10:161-166. https://doi.org/10. 1111/j.1447-0594.2009.00571.x

Hill RL, Kulbe JR, Singh IN, Wang JA, Hall ED (2018) Synaptic mitochondria are more susceptible to traumatic brain injury-induced oxidative damage and respiratory dysfunction than non-synaptic mitochondria. Neuroscience 386:265-283. https://doi.org/10. 1016/j.neuroscience.2018.06.028

Hill RL, Singh IN, Wang JA, Hall ED (2017) Time courses of postinjury mitochondrial oxidative damage and respiratory dysfunction and neuronal cytoskeletal degradation in a rat model of focal traumatic brain injury. Neurochem Int 111:45-56. https://doi.org/ 10.1016/j.neuint.2017.03.015

Hill RL, Singh IN, Wang JA, Hall ED (2019) Effects of phenelzine administration on mitochondrial function, calcium handling, and cytoskeletal degradation after experimental traumatic brain injury. J Neurotrauma 36:1231-1251. https://doi.org/10.1089/ neu.2018.5946

Hill RL, Singh IN, Wang JA, Kulbe JR, Hall ED (2020) Protective effects of phenelzine administration on synaptic and non-synaptic cortical mitochondrial function and lipid peroxidation-mediated oxidative damage following TBI in young adult male rats. Exp Neurol 330:113322. https://doi.org/10.1016/j.expneurol.2020. 113322

Hogard ML, Lunte CE, Lunte SM (2017) Detection of reactive aldehyde biomarkers in biological samples using solid-phase extraction pre-concentration and liquid chromatography with fluorescence detection. Anal Methods 9:1848-1854. https://doi.org/10. 1039/C6AY03327J

Holt A, Berry MD, Boulton AA (2004) On the binding of monoamine oxidase inhibitors to some sites distinct from the MAO active site, and effects thereby elicited. Neurotoxicology 25:251-266

Holt A, Palcic MM (2006) A peroxidase-coupled continuous absorbance plate-reader assay for flavin monoamine oxidases, coppercontaining amine oxidases and related enzymes. Nat Protoc 1(5):2498-2505. https://doi.org/10.1038/nprot.2006.402

Horita A (1965) The initial inactivation of phenelzine by a monoamine oxidase-like system in vitro and in vivo. Br J Pharmacol Chemother 24:245-252. https://doi.org/10.1111/j.1476-5381.1965. tb02100.x

Horváth Á, Menghis A, Botz B et al (2017) Analgesic and anti-inflammatory effects of the novel semicarbazide-sensitive amine-oxidase inhibitor $\mathrm{SzV}-1287$ in chronic arthritis models of the mouse. Sci Rep 7:39863. https://doi.org/10.1038/srep39863

Houen G, Bock K, Jensen AL (1994) HPLC and NMR investigation of the serum amine oxidase catalyzed oxidation of polyamines. Acta Chem Scand 48:52-60

Huang YJ, Jin MH, Pi RB et al (2013) Acrolein induces Alzheimer's disease-like pathologies in vitro and in vivo. Toxicol Lett 217:184-191. https://doi.org/10.1016/j.toxlet.2012.12.023

Hunsberger J, Austin DR, Henter ID, Chen G (2009) The neurotrophic and neuroprotective effects of psychotropic agents. Dialogues Clin Neurosci 11:333-348. https://doi.org/10.31887/DCNS. 2009.11.3/jhunsberger

Hunter MIS, Nlemadim BC, Davidson DLW (1985) Lipid peroxidation products and antioxidant proteins in plasma and cerebrospinal fluid from multiple sclerosis patients. Neurochem Res 10:1645-1652

Ilic TV, Jovanovic M, Jovicic A, Tomovic M (1999) Oxidative stress indicators are elevated in de novo Parkinson's disease patients. Funct Neurol 14:141-147

Ivanova S, Botchkina G, Al-Abed Y et al (1998) Cerebral ischemia enhances polyamine oxidation: identification of enzymatically formed 3-aminopropanal as an endogenous mediator of neuronal and glial cell death. J Exp Med 188:327-340

Jarnicki AG, Schilter H, Liu G et al (2016) The inhibitor of semicarbazide-sensitive amine oxidase, PXS-4728A, ameliorates key features of chronic obstructive pulmonary disease in a mouse model. Br J Pharmacol 173:3161-3175. https://doi.org/10.1111/ bph.13573

Jarrahi A, Braun M, Ahluwalia M et al (2020) Revisiting traumatic brain injury: from molecular mechanisms to therapeutic interventions. Biomedicines. https://doi.org/10.3390/biomedicin es8100389

Jiang ZJ, Richardson JS, Yu PH (2008) The contribution of cerebral vascular semicarbazide-sensitive amine oxidase to cerebral amyloid angiopathy in Alzheimer's disease. Neuropathol Appl Neurobiol 34:194-204. https://doi.org/10.1111/j.1365-2990.2007. 00886.x

Jo S, Yarishkin O, Hwang YE et al (2014) GABA from reactive astrocytes impairs memory in mouse models of Alzheimer's disease. Nat Med. https://doi.org/10.1038/nm.3639

Joseph TP, Jagadeesan N, Sai LY, Lin SL, Sahu S, Schachner M (2020) Adhesion molecule L1 agonist mimetics protect against the pesticide paraquat-induced locomotor deficits and biochemical alterations in zebrafish. Front Neurosci 14:458. https://doi.org/ 10.3389/fnins.2020.00458

Jossan S, Gillberg P, Gottfries C, Karlsson I, Oreland L (1991) Monoamine oxidase B in brains from patients with Alzheimer's disease: a biochemical and autoradiographical study. Neuroscience 45:1-12. https://doi.org/10.1016/0306-4522(91)90098-9

Jossan SS, Hiraga Y, Oreland L (1989) The cholinergic neurotoxin ethylcholine mustard aziridinium (AF64A) induces an increase in MAO-B activity in the rat brain. Brain Res 476:291-297

Kennedy S, Holt A, Baker G (2009) Monoamine oxidase inhibitors. In: Sadock B, Sadock V, Ruiz P (eds) Comprehensive textbook of psychiatry. Lippincott Williams and Wilkins, New York, pp 3154-3164

Ketter TA, Wang PW (2003) The emerging differential roles of GABAergic and antiglutamatergic agents in bipolar disorders. J Clin Psychiatry 64(Suppl 3):15-20

Khoramjouy M, Naderi N, Kobarfard F, Heidarli E, Faizi M (2020) An intensified acrolein exposure can affect memory and cognition in rat. Neurotox Res. https://doi.org/10.1007/s12640-020-00278-x

Kim YS, Yoon BE (2017) Altered GABAergic signaling in brain disease at various stages of life. Exp Neurobiol 26:122-131. https:// doi.org/10.5607/en.2017.26.3.122

Kiss J, Jalkanen S, Fülöp F, Savunen T, Salmi M (2008) Ischemiareperfusion injury is attenuated in VAP-1-deficient mice and by VAP-1 inhibitors. Eur J Immunol 38:3041-3049. https://doi.org/ 10.1002/eji.200838651

Kuhla B, Haase C, Flach K, Luth HJ, Arendt T, Munch G (2007) Effect of pseudophosphorylation and cross-linking by lipid peroxidation and advanced glycation end product precursors on tau aggregation and filament formation. J Biol Chem 282:6984-6991. https:// doi.org/10.1074/jbc.M609521200

Kulbe JR, Singh IN, Wang JA, Cebak JE, Hall ED (2018) Continuous infusion of phenelzine, cyclosporine A, or their combination: evaluation of mitochondrial bioenergetics, oxidative damage, and cytoskeletal degradation following severe controlled cortical impact traumatic brain injury in rats. J Neurotrauma 35:12801293. https://doi.org/10.1089/neu.2017.5353

Kumpula D, Rauw G, MacKenzie E, Dursun S, Baker G (2010) $\beta$-Phenylethylamine and $\beta$-phenylethylidenehydrazine are important metabolites of the MAO inhibitor phenelzine. In: Proceedings of the joint annual meeting of Canadian College of Neuropsychopharmacology and Canadian Association of Neuroscience, Ottawa, ON, Canada 
Lee CS, Han ES, Lee WB (2003) Antioxidant effect of phenelzine on $\mathrm{MPP}^{+}$-induced cell viability loss in differentiated PC12 cells. Neurochem Res 28:1833-1841

Lee SE, Park YS (2013) Role of lipid peroxidation-derived $\alpha$, $\beta$-unsaturated aldehydes in vascular dysfunction. Oxid Med Cell Longev 2013:629028. https://doi.org/10.1155/2013/629028

Leker RR, Neufeld MY (2003) Anti-epileptic drugs as possible neuroprotectants in cerebral ischemia. Brain Res Rev 42:187-203. https://doi.org/10.1016/s0165-0173(03)00170-x

Leung G, Sun W, Zheng L, Brookes S, Tully M, Shi R (2011) Antiacrolein treatment improves behavioral outcome and alleviates myelin damage in experimental autoimmune encephalomyelitis mouse. Neuroscience 173:150-155. https://doi.org/10.1016/j. neuroscience.2010.11.018

Li R, Sahu S, Schachner M (2018) Phenelzine, a cell adhesion molecule L1 mimetic small organic compound, promotes functional recovery and axonal regrowth in spinal cord-injured zebrafish. Pharmacol Biochem Behav 171:30-38. https://doi.org/10.1016/j. pbb.2018.05.013

Li XH, Xie JZ, Jiang X et al (2012) Methylglyoxal induces tau hyperphosphorylation via promoting AGEs formation. Neuromol Med 14:338-348. https://doi.org/10.1007/s12017-012-8191-0

Li XM, Xu H (2007) Evidence for neuroprotective effects of antipsychotic drugs: implications for the pathophysiology and treatment of schizophrenia. Int Rev Neurobiol 77:107-142. https://doi.org/ 10.1016/s0074-7742(06)77004-0

Lieberman JA, Bymaster FP, Meltzer HY et al (2008) Antipsychotic drugs: comparison in animal models of efficacy, neurotransmitter regulation, and neuroprotection. Pharmacol Rev 60:358-403. https://doi.org/10.1124/pr.107.00107

Liebowitz MR, Gorman JM, Fyer AJ et al (1988) Pharmacotherapy of social phobia: an interim report of a placebo-controlled comparison of phenelzine and atenolol. J Clin Psychiatry 49:252-257

Lin Y, Chen Z, Tang J, Cao P, Shi R (2018) Acrolein contributes to the neuropathic pain and neuron damage after ischemic-reperfusion spinal cord injury. Neuroscience 384:120-130. https://doi.org/ 10.1016/j.neuroscience.2018.05.029

Liu X, Erikson C, Brun A (1996) Cortical synaptic changes and gliosis in normal aging, Alzheimer's disease and frontal lobe degeneration. Dementia 7:128-134

Liu-Snyder P, Borgens RB, Shi R (2006) Hydralazine rescues PC12 cells from acrolein-mediated death. J Neurosci Res 84:219-227. https://doi.org/10.1002/jnr.20862

Lizcano JM, Fernández de Arriba A, Tipton KF, Unzeta M (1996) Inhibition of bovine lung semicarbazide-sensitive amine oxidase (SSAO) by some hydrazine derivatives. Biochem Pharmacol 52:187-195

Lorigados Pedre L, Gallardo JM, Morales Chacon LM et al (2018) Oxidative stress in patients with drug resistant partial complex seizure. Behav Sci. https://doi.org/10.3390/bs8060059

Lovell MA, Xie C, Markesbery WR (2001) Acrolein is increased in Alzheimer's disease brain and is toxic to primary hippocampal cultures. Neurobiol Aging 22:187-194

Luscher B, Shen Q, Sahir N (2011) The GABAergic deficit hypothesis of major depressive disorder. Mol Psychiatry 16:383-406. https://doi.org/10.1038/mp.2010.120

Lyles GA (1996) Mammalian plasma and tissue-bound semicarbazidesensitive amine oxidases: biochemical, pharmacological and toxicological aspects. Int J Biochem Cell Biol 28:259-274

Lyles GA, Chalmers J (1992) The metabolism of aminoacetone to methylglyoxal by semicarbazide-sensitive amine oxidase in human umbilical artery. Biochem Pharmacol 43:1409-1414

Lyles GA, Holt A, Marshall CM (1990) Further studies on the metabolism of methylamine by semicarbazide-sensitive amine oxidase activities in human plasma, umbilical artery and rat aorta. $\mathbf{J}$ Pharm Pharmacol 42:332-338
Ma Q, Manaenko A, Khatibi NH, Chen W, Zhang JH, Tang J (2011) Vascular adhesion protein-1 inhibition provides antiinflammatory protection after an intracerebral hemorrhagic stroke in mice. J Cereb Blood Flow Metab 31:881-893. https://doi.org/10.1038/ jcbfm.2010.167

MacKenzie EM (2009) Neurochemical and neuroprotective aspects of phenelzine and its active metabolite $\beta$-phenylethylidenehydrazine. PhD Thesis, University of Alberta

MacKenzie EM, Fassihi A, Davood A et al (2008a) $N$-propynyl analogs of $\beta$-phenylethylidenehydrazines: synthesis and evaluation of effects on glycine, GABA, and monoamine oxidase. Bioorg Med Chem 16:8254-8263. https://doi.org/10.1016/j.bmc.2008.07.027

MacKenzie EM, Grant SL, Baker GB, Wood PL (2008b) Phenelzine causes an increase in brain ornithine that is prevented by prior monoamine oxidase inhibition. Neurochem Res. https://doi. org/10.1007/s11064-007-9448-0

MacKenzie EM, Song MS, Dursun SM, Tomlinson S, Todd KG, Baker GB (2010) Phenelzine: an old drug that may hold clues to the development of new neuroprotective agents. Bull Clin Psychopharmacol 20:179-186

Magyar K, Szende B (2004) (-)-Deprenyl, a selective MAO-B inhibitor, with apoptotic and anti-apoptotic properties. Neurotoxicology 25:233-242. https://doi.org/10.1016/S0161-813X(03) 00102-5

Manzoor S, Hoda N (2020) A comprehensive review of monoamine oxidase inhibitors as Anti-Alzheimer's disease agents: a review. Eur J Med Chem 206:112787. https://doi.org/10.1016/j. ejmech.2020.112787

Marchitti SA, Deitrich RA, Vasiliou V (2007) Neurotoxicity and metabolism of the catecholamine-derived 3,4-dihydroxyphenylacetaldehyde and 3,4-dihydroxyphenylglycolaldehyde: the role of aldehyde dehydrogenase. Pharmacol Rev 59:125-150. https://doi.org/10.1124/pr.59.2.1

Marcus DL, Thomas C, Rodriguez C, Simberkoff K, Tsai JS, Strafaci JA, Freedman ML (1998) Increased peroxidation and reduced antioxidant enzyme activity in Alzheimer's disease. Exp Neurol 150:40-44. https://doi.org/10.1006/exnr.1997.6750

Martin-Aragon S, Bermejo-Bescos P, Benedi J, Felici E, Gil P, Ribera JM, Villar AM (2009) Metalloproteinase's activity and oxidative stress in mild cognitive impairment and Alzheimer's disease. Neurochem Res 34:373-378. https://doi.org/10.1007/ s11064-008-9789-3

Masato A, Plotegher N, Boassa D, Bubacco L (2019) Impaired dopamine metabolism in Parkinson's disease pathogenesis. Mol Neurodegener 14:35. https://doi.org/10.1186/ s13024-019-0332-6

Matveychuk D (2015) Novel properties of the multifaceted drug phenelzine and its metabolite $\beta$-phenylethylidenehydrazine. $\mathrm{PhD}$ Thesis, University of Alberta

Matveychuk D, Dursun S, Wood P, Baker G (2011) Reactive aldehydes and neurodegenerative disorders. Bull Clin Psychopharmacol 21:277-288. https://doi.org/10.5455/bcp.19691231040000

Matveychuk D, Nunes E, Ullah N, Velazquez-Martinez CA, MacKenzie EM, Baker GB (2013) Comparison of phenelzine and geometric isomers of its active metabolite, beta-phenylethylidenehydrazine, on rat brain levels of amino acids, biogenic amine neurotransmitters and methylamine. J Neural Transm 120:987-996. https://doi. org/10.1007/s00702-013-0978-0

McGrath PJ, Stewart JW, Harrison W, Wager S, Quitkin FM (1986) Phenelzine treatment of melancholia. J Clin Psychiatry 47:420-422

McKenna KF, McManus DJ, Baker GB, Coutts RT (1994) Chronic administration of the antidepressant phenelzine and its $\mathrm{N}$-acetyl analogue: effects on GABAergic function. J Neural Transm Suppl 41:115-122 
Mifflin KA, Benson C, Thorburn KC, Baker GB, Kerr BJ (2016) Manipulation of neurotransmitter levels has differential effects on formalin-evoked nociceptive behavior in male and female mice. J Pain 17:483-498. https://doi.org/10.1016/j.jpain.2015.12.013

Moghe A, Ghare S, Lamoreau B, Mohammad M, Barve S, McClain C, Joshi-Barve S (2015) Molecular mechanisms of acrolein toxicity: relevance to human disease. Toxicol Sci 143:242-255. https:// doi.org/10.1093/toxsci/kfu233

Musgrave T, Benson C, Wong G et al (2011) The MAO inhibitor phenelzine improves functional outcomes in mice with experimental autoimmune encephalomyelitis (EAE). Brain Behav Immun 25:1677-1688. https://doi.org/10.1016/j.bbi.2011.06.011

Mustafa AG, Al-Shboul O, Alfaqih MA, Al-Qudah MA, Al-Dwairi AN (2018a) Phenelzine reduces the oxidative damage induced by peroxynitrite in plasma lipids and proteins. Arch Physiol Biochem 124:418-423. https://doi.org/10.1080/13813455.2017. 1415939

Mustafa AG, Alfaqih MA, Al-Shboul O (2018b) The 4-hydroxynonenal mediated oxidative damage of blood proteins and lipids involves secondary lipid peroxidation reactions. Exp Ther Med 16:21322137. https://doi.org/10.3892/etm.2018.6419

Nam DT, Arseneault M, Murthy V, Ramassamy C (2010) Potential role of acrolein in neurodegeneration and in Alzheimer's disease. Curr Mol Pharmacol 3:66-78

Naylor DE (2010) Glutamate and GABA in the balance: convergent pathways sustain seizures during status epilepticus. Epilepsia 51(Suppl 3):106-109. https://doi.org/10.1111/j.1528-1167.2010. 02622.x

Ng F, Berk M, Dean O, Bush AI (2008) Oxidative stress in psychiatric disorders: evidence base and therapeutic implications. Int J Neuropsychopharmacol 11:851-876. https://doi.org/10.1017/ s1461145707008401

Nibuya M, Morinobu S, Duman RS (1995) Regulation of BDNF and trkB mRNA in rat brain by chronic electroconvulsive seizure and antidepressant drug treatments. J Neurosci 15:7539-7547

Niemann B, Rohrbach S, Miller MR, Newby DE, Fuster V, Kovacic JC (2017) Oxidative stress and cardiovascular risk: obesity, diabetes, smoking, and pollution: part 3 of a 3-part series. J Am Coll Cardiol 70:230-251. https://doi.org/10.1016/j.jacc.2017.05.043

O'Brien PJ, Siraki AG, Shangari N (2005) Aldehyde sources, metabolism, molecular toxicity mechanisms, and possible effects on human health. Crit Rev Toxicol 35:609-662

O'Rourke AM, Wang EY, Salter-Cid L et al (2007) Benefit of inhibiting SSAO in relapsing experimental autoimmune encephalomyelitis. J Neural Transm 114:845. https://doi.org/10.1007/ s00702-007-0699-3

Olowe R, Sandouka S, Saadi A, Shekh-Ahmad T (2020) Approaches for reactive oxygen species and oxidative stress quantification in epilepsy. Antioxidants. https://doi.org/10.3390/antiox9100990

Oreland L, Gottfries CG (1986) Brain and brain monoamine oxidase in aging and in dementia of Alzheimer's type. Prog Neuro-Psychopharmacol Biol Psychiatry 10:533-540

Ou J, Zhang Y, Montine T (2002) In vivo assessment of lipid peroxidation products associated with age-related neurodegenerative diseases. Exp Neurol 175:363-369. https://doi.org/10.1006/exnr. 2002.7923

Padurariu M, Ciobica A, Hritcu L, Stoica B, Bild W, Stefanescu C (2010) Changes of some oxidative stress markers in the serum of patients with mild cognitive impairment and Alzheimer's disease. Neurosci Lett 469:6-10. https://doi.org/10.1016/j.neulet. 2009.11.033

Pannecoeck R, Serruys D, Benmeridja L, Delanghe JR, van Geel N, Speeckaert R, Speeckaert MM (2015) Vascular adhesion protein-1: role in human pathology and application as a biomarker. Crit Rev Clin Lab Sci 52:284-300. https://doi.org/10.3109/10408 363.2015.1050714
Panneton WM, Kumar VB, Gan Q, Burke WJ, Galvin JE (2010) The neurotoxicity of DOPAL: behavioral and stereological evidence for its role in Parkinson disease pathogenesis. PLoS ONE 5:e15251. https://doi.org/10.1371/journal.pone.0015251

Park J, Zheng L, Acosta G et al (2015) Acrolein contributes to TRPA1 up-regulation in peripheral and central sensory hypersensitivity following spinal cord injury. J Neurochem 135:987-997. https:// doi.org/10.1111/jnc. 13352

Park J-H, Ju YH, Choi JW et al (2019) Newly developed reversible MAO-B inhibitor circumvents the shortcomings of irreversible inhibitors in Alzheimer's disease. Sci Adv 5:eaav0316. https:// doi.org/10.1126/sciadv.aav0316

Paslawski T, Knaus E, Iqbal N, Coutts R, Baker G (2001) $\beta$-Phenylethylidenehydrazine, a novel inhibitor of GABA transaminase. Drug Dev Res 54:35-39

Paslawski TM, Sloley BD, Baker GB (1995) Effects of the MAO inhibitor phenelzine on glutamine and GABA concentrations in rat brain. Prog Brain Res 106:181-186

Patek DR, Hellerman L (1974) Mitochondrial monoamine oxidase. Mechanism of inhibition by phenylhydrazine and by aralkylhydrazines. Role of enzymatic oxidation. J Biol Chem 249:2373-2380

Perluigi M, Coccia R, Butterfield DA (2012) 4-Hydroxy-2-nonenal, a reactive product of lipid peroxidation, and neurodegenerative diseases: a toxic combination illuminated by redox proteomics studies. Antioxid Redox Signal 17:1590-1609. https://doi.org/ 10.1089/ars.2011.4406

Phani S, Loike JD, Przedborski S (2012) Neurodegeneration and inflammation in Parkinson's disease. Parkinsonism Relat Disord 18(Suppl 1):S207-S209. https://doi.org/10.1016/s13538020(11)70064-5

Popov N, Matthies H (1969) Some effects of monoamine oxidase inhibitors on the metabolism of gamma-aminobutyric acid in rat brain. J Neurochem 16:899-907

Potter LE, Doolen S, Mifflin K, Tenorio G, Baker G, Taylor BK, Kerr BJ (2018) Antinociceptive effects of the antidepressant phenelzine are mediated by context-dependent inhibition of neuronal responses in the dorsal horn. Neuroscience 383:205-215. https://doi.org/10.1016/j.neuroscience.2018.04.047

Potter LE, Paylor JW, Suh JS et al (2016) Altered excitatory-inhibitory balance within somatosensory cortex is associated with enhanced plasticity and pain sensitivity in a mouse model of multiple sclerosis. J Neuroinflamm 13:142-142. https://doi. org/10.1186/s12974-016-0609-4

Practico D (2008) Oxidative stress hypothesis in Alzheimer's disease: a reappraisal. Trends Pharmacol Sci 29(12):609-615

Quartey MO, Nyarko JNK, Pennington PR, Heistad RM, Klassen PC, Baker GB, Mousseau DD (2018) Alzheimer disease and selected risk factors disrupt a co-regulation of monoamine oxidase-A/B in the hippocampus, but not in the cortex. Front Neurosci 12:419. https://doi.org/10.3389/fnins.2018.00419

Reed TT (2011) Lipid peroxidation and neurodegenerative disease. Free Radic Biol Med 51:1302-1319. https://doi.org/10.1016/j. freeradbiomed.2011.06.027

Reinikainen KJ, Paljarvi L, Halonen T, Malminen O, Kosma VM, Laakso M, Riekkinen PJ (1988) Dopaminergic system and monoamine oxidase-B activity in Alzheimer's disease. Neurobiol Aging 9:245-252

Ribaudo G, Bortoli M, Pavan C, Zagotto G, Orian L (2020) Antioxidant potential of psychotropic drugs: from clinical evidence to in vitro and in vivo assessment and toward a new challenge for in silico molecular design. Antioxidants. https://doi.org/10. 3390/antiox 9080714

Riederer P, Danielczyk W, Grunblatt E (2004) Monoamine oxidase-B inhibition in Alzheimer's disease. Neurotoxicology 25:271-277 
Riederer P, Konradi C, Schay V et al (1987) Localization of MAO-A and MAO-B in human brain: a step in understanding the therapeutic action of L-deprenyl. Adv Neurol 45:111-118

Robinson DS, Cooper TB, Jindal SP, Corcella J, Lutz T (1985) Metabolism and pharmacokinetics of phenelzine: lack of evidence for acetylation pathway in humans. J Clin Psychopharmacol 5:333-337

Romano A, Serviddio G, Calcagnini S, Villani R, Giudetti AM, Cassano T, Gaetani S (2017) Linking lipid peroxidation and neuropsychiatric disorders: focus on 4-hydroxy-2-nonenal. Free Radic Biol Med 111:281-293. https://doi.org/10.1016/j.freer adbiomed.2016.12.046

Sa JM, Barros MC, Melo MR et al (2019) Endogenous hydrogen peroxide affects antidiuresis to cholinergic activation in the medial septal area. Neurosci Lett 694:51-56

Salmi M, Jalkanen S (2001) VAP-1: an adhesin and an enzyme. Trends Immunnol 22(4):211-216. https://doi.org/10.1016/s14714906(01)01870-1

Saura J, Luque JM, Cesura AM et al (1994) Increased monoamine oxidase B activity in plaque-associated astrocytes of Alzheimer brains revealed by quantitative enzyme radioautography. Neuroscience 62:15-30. https://doi.org/10.1016/0306-4522(94) 90311-5

Schain M, Kreisl WC (2017) Neuroinflammation in neurodegenerative disorders-a review. Curr Neurol Neurosci Rep 17:25. https://doi. org/10.1007/s11910-017-0733-2

Schedin-Weiss S, Inoue M, Hromadkova L et al (2017) Monoamine oxidase B is elevated in Alzheimer disease neurons, is associated with $\gamma$-secretase and regulates neuronal amyloid $\beta$-peptide levels. Alzheimers Res Ther 9:57. https://doi.org/10.1186/ s13195-017-0279-1

Schneider LS, Mangialasche F, Andreasen N et al (2014) Clinical trials and late-stage drug development for Alzheimer's disease: an appraisal from 1984 to 2014. J Intern Med 275:251-283. https:// doi.org/10.1111/joim.12191

Schwartz-Bloom RD, Sah R (2001) $\gamma$-Aminobutyric acid neurotransmission and cerebral ischemia. J Neurochem 77:353-371

Selkoe DJ (2001) Alzheimer's disease: genes, proteins, and therapy. Physiol Rev 81:741-766

Serra JA, Dominguez RO, Marschoff ER, Guareschi EM, Famulari AL, Boveris A (2009) Systemic oxidative stress associated with the neurological diseases of aging. Neurochem Res 34:2122-2132. https://doi.org/10.1007/s11064-009-9997-5

Shadfar S, Kim Y-G, Katila N et al (2018) Neuroprotective effects of antidepressants via upregulation of neurotrophic factors in the MPTP Model of Parkinson's disease. Mol Neurobiol 55:554566. https://doi.org/10.1007/s12035-016-0342-0

Shamoto-Nagai M, Maruyama W, Hashizume Y, Yoshida M, Osawa T, Riederer P, Naoi M (2007) In parkinsonian substantia nigra, $\alpha$-synuclein is modified by acrolein, a lipid-peroxidation product, and accumulates in the dopamine neurons with inhibition of proteasome activity. J Neural Transm 114:1559-1567. https:// doi.org/10.1007/s00702-007-0789-2

Shanahan P, O'Sullivan J, Tipton KF, Kinsella GK, Ryan BJ, Henehan GTM (2019) Theobromine and related methylxanthines as inhibitors of Primary Amine Oxidase. J Food Biochem 43:e12697. https://doi.org/10.1111/jfbc.12697

Sheehan DV, Ballenger J, Jacobsen G (1980) Treatment of endogenous anxiety with phobic, hysterical, and hypochondriacal symptoms. Arch Gen Psychiatry 37:51-59

Shemyakov SE (2001) Monoamine oxidase activity, lipid peroxidation, and morphological changes in human hypothalamus during aging. Bull Exp Biol Med 131:586-588

Sherif F, Gottfries CG, Alafuzoff I, Oreland L (1992) Brain gammaaminobutyrate aminotransferase (GABA-T) and monoamine oxidase (MAO) in patients with Alzheimer's disease. J Neural Transm Parkinson Dis Dement Sect 4:227-240

Shi R, Page JC, Tully M (2015) Molecular mechanisms of acroleinmediated myelin destruction in CNS trauma and disease. Free Radic Res 49:888-895. https://doi.org/10.3109/10715762.2015. 1021696

Shi Y, Sun W, McBride JJ, Cheng JX, Shi R (2011) Acrolein induces myelin damage in mammalian spinal cord. J Neurochem 117:554-564. https://doi.org/10.1111/j.1471-4159.2011.07226.x

Shuaib A, Ijaz MS, Miyashita H, Hussain S, Kanthan R (1997) GABA and glutamate levels in the substantia nigra reticulata following repetitive cerebral ischemia in gerbils. Exp Neurol 147:311-315. https://doi.org/10.1006/exnr.1997.6588

Shuaib A, Ijaz S, Hasan S, Kalra J (1992) Gamma-vinyl GABA prevents hippocampal and substantia nigra reticulata damage in repetitive transient forebrain ischemia. Brain Res 590:13-17

Shuaib A, Kanthan R (1997) Amplification of inhibitory mechanisms in cerebral ischemia: an alternative approach to neuronal protection. Histol Histopathol 12:185-194

Sinem F, Dildar K, Gokhan E, Melda B, Orhan Y, Filiz M (2010) The serum protein and lipid oxidation marker levels in Alzheimer's disease and effects of cholinesterase inhibitors and antipsychotic drugs therapy. Curr Alzheimer Res 7:463-469

Singh IN, Gilmer LK, Miller DM, Cebak JE, Wang JA, Hall ED (2013) Phenelzine mitochondrial functional preservation and neuroprotection after traumatic brain injury related to scavenging of the lipid peroxidation-derived aldehyde 4-hydroxy-2-nonenal. J Cereb Blood Flow Metab 33:593-599. https://doi.org/10.1038/ jcbfm.2012.211

Song MS, Baker GB, Dursun SM, Todd KG (2010) The antidepressant phenelzine protects neurons and astrocytes against formaldehyde-induced toxicity. J Neurochem 114:1405-1413. https:// doi.org/10.1111/j.1471-4159.2010.06857.x

Song MS, Matveychuk D, MacKenzie EM, Duchcherer M, Mousseau DD, Baker GB (2013) An update on amine oxidase inhibitors: multifaceted drugs. Prog Neuropsychopharmacol Biol Psychiatry 44:118-124. https://doi.org/10.1016/j.pnpbp.2013.02.001

Sowa B, Knaus E, Todd K, Davood A, Baker G (2003) Biochemical activity of 4-fluorophenylethylidenehydrazine and its potential as a neuroprotectant in cerebral ischemia. J Neurochem 85(Suppl 1): 10

Sowa B, Rauw G, Davood A, Fassihi A, Knaus E, Baker G (2005) Design and evaluation of phenyl substituted analogs of beta-phenylethylidenehydrazine. Bioorg Med Chem 13(14):4389-4395

Sowa BN, Todd KG, Tanay VAMI, Holt A, Baker GB (2004) Amine oxidase inhibitors and development of neuroprotective drugs. Curr Neuropharmacol 2:153-168

Sparks DL, Woeltz VM, Markesbery WR (1991) Alterations in brain monoamine oxidase activity in aging, Alzheimer's disease, and Pick's disease. Arch Neurol 48:718-721

Stolen CM, Yegukin GG, Kurkijarvi R, Bono P, Alitalo K, Jalkanen S (2004) Origins of serum semicarbazide-sensitive amine oxidase. Circ Res 95:50-57. https://doi.org/10.1161/01.res.0000134630. 68877.2f

Stumm R, Culmsee C, Schafer MK, Krieglstein J, Weihe E (2001) Adaptive plasticity in tachykinin and tachykinin receptor expression after focal cerebral ischemia is differentially linked to GABAergic and glutamatergic cerebrocortical circuits and cerebrovenular endothelium. J Neurosci 21:798-811. https://doi.org/ 10.1523/jneurosci.21-03-00798.2001

Sturm S, Forsberg A, Nave S et al (2017) Positron emission tomography measurement of brain MAO-B inhibition in patients with Alzheimer's disease and elderly controls after oral administration of sembragiline. Eur J Nucl Med Imaging 44:382-391 
Sugamura K, Keaney JF Jr (2011) Reactive oxygen species in cardiovascular disease. Free Radic Biol Med 51:978-992. https://doi. org/10.1016/j.freeradbiomed.2011.05.004

Sultana R, Perluigi M, Butterfield DA (2013) Lipid peroxidation triggers neurodegeneration: a redox proteomics view into the Alzheimer disease brain. Free Radic Biol Med 62:157-169. https:// doi.org/10.1016/j.freeradbiomed.2012.09.027

Sydserff SG, Cross AJ, Murray TK, Jones JA, Green AR (2000) Clomethiazole is neuroprotective in models of global and focal cerebral ischemia when infused at doses producing clinically relevant plasma concentrations. Brain Res 862:59-62. https://doi.org/ 10.1016/s0006-8993(00)02071-0

Szökő É, Tábi T, Riederer P, Vécsei L, Magyar K (2018) Pharmacological aspects of the neuroprotective effects of irreversible MAO-B inhibitors, selegiline and rasagiline, in Parkinson's disease. J Neural Transm 125:1735-1749. https://doi.org/10.1007/ s00702-018-1853-9

Tabi T, Vecsel L, Youdim MB et al (2020) Selegiline: a molecule with innovative potential. J Neural Transm 127:831-842

Tanay VA, Todd KG, Baker GB (2002) Phenylethylidenehydrazine, a novel GABA-T inhibitor, rescues neurons from cerebral ischemia. In: Proceedings of the 23rd congress of the Collegium Internationale Neuropsychopharmacologicum Montreal, Canada

Tanzi RE, Bertram L (2005) Twenty years of the Alzheimer's disease amyloid hypothesis: a genetic perspective. Cell 120:545-555. https://doi.org/10.1016/j.cell.2005.02.008

Taso OV, Philippou A, Moustogiannis A, Zevolis E, Koutsilieris M (2019) Lipid peroxidation products and their role in neurodegenerative diseases. Ann Res Hosp. https://doi.org/10.21037/ arh.2018.12.02

Tatton W, Chalmers-Redman R, Tatton N (2003) Neuroprotection by deprenyl and other propargylamines: glyceraldehyde3-phosphate dehydrogenase rather than monoamine oxidase B. J Neural Transm 110:509-515. https://doi.org/10.1007/ s00702-002-0827-z

Tipton KF (1971) The reaction of monoamine oxidase with phenethylhydrazine. Biochem J 121:33P-34P

Tipton KF (1972) Inhibition of monoamine oxidase by substituted hydrazines. Biochem J 128:913-919

Tipton KF, Spires IP (1972) Oxidation of 2-phenylethylhydrazine by monoamine oxidase. Biochem Pharmacol 21:268-270

Todd KG, Baker GB (1995) GABA-elevating effects of the antidepressant/antipanic drug phenelzine in brain: effects of pretreatment with tranylcypromine, (-)-deprenyl and clorgyline. J Affect Disord 35:125-129

Todd KG, Baker GB (2008) Neurochemical effects of the monoamine oxidase inhibitor phenelzine on brain GABA and alanine: a comparison with vigabatrin. J Pharm Pharm Sci 11:14s-21s

Todd KG, Banigesh AI, Baker GB, Coutts RT, Shuaib A (1999) Phenylethylidenehydrazine, a novel GABA-T inhibitor, has neuroprotective actions in transient global ischemia. J Neurochem 73(Suppl. S202B)

Troubat R, Barone P, Leman S et al (2020) Neuroinflammation and depression: a review. Eur J Neurosci. https://doi.org/10.1111/ ejn. 14720

Tully M, Tang J, Zheng L et al (2018) Systemic acrolein elevations in mice with experimental autoimmune encephalomyelitis and patients with multiple sclerosis. Front Neurol 9:420. https://doi. org/10.3389/fneur.2018.00420

Uchida K, Kanematsu M, Saka K et al (1998) Protein-bound acrolein: potential markers for oxidative stress. Proc Natl Acad Sci USA 95:4882-4887

Unzeta M, Solé M, Boada M, Hernández M (2007) Semicarbazidesensitive amine oxidase (SSAO) and its possible contribution to vascular damage in Alzheimer's disease. J Neural Transm 114:857-862. https://doi.org/10.1007/s00702-007-0701-0

Valente T, Gella A, Solé M, Durany N, Unzeta M (2012) Immunohistochemical study of semicarbazide-sensitive amine oxidase/vascular adhesion protein- 1 in the hippocampal vasculature: pathological synergy of Alzheimer's disease and diabetes mellitus. J Neurosci Res 90:1989-1996. https://doi.org/10.1002/jnr.23092

Volchegorskii IA, Shemyakov SE, Turygin VV, Malinovskaya NV (2001) Comparative analysis of age-related changes in activities of monoamine oxidase-B and antioxidant defense enzymes in various structures of human brain. Bull Exp Biol Med $132: 760-762$

Wang W, Gao C, Hou XY, Liu Y, Zong YY, Zhang GY (2004) Activation and involvement of JNK1/2 in hydrogen peroxide-induced neurotoxicity in cultured rat cortical neurons. Acta Pharmacol Sin 25:630-636

Wassef A, Baker J, Kochan LD (2003) GABA and schizophrenia: a review of basic science and clinical studies. J Clin Psychopharmacol 23:601-640. https://doi.org/10.1097/01.jcp.0000095349. 32154.a5

Williams T, Lynn B, Markesbery W, Lovell M (2006) Increased levels of 4-hydroxynonenal and acrolein, neurotoxic markers of lipid peroxidation, in the brain in mild cognitive impairment and early Alzheimer's disease. Neurobiol Aging 27:1094-1099. https://doi. org/10.1016/j.neurobiolaging.2005.06.004

Williams T, McCaul M, Schwarzer G, Cipriani A, Stein DJ, Ipser J (2020) Pharmacological treatments for social anxiety disorder in adults: a systematic review and network meta-analysis. Acta Neuropsychiatr 32:169-176. https://doi.org/10.1017/neu.2020.6

Wood JA, Wood PL, Ryan R, Graff-Radford NR, Pilapil C, Robitaille Y, Quirion R (1993) Cytokine indices in Alzheimer's temporal cortex: no changes in mature IL-1 beta or IL-1RA but increases in the associated acute phase proteins IL-6, alpha 2-macroglobulin and C-reactive protein. Brain Res 629:245-252. https://doi. org/10.1016/0006-8993(93)91327-o

Wood P (2006) Neurodegeneration and aldehyde load: from concept to therapeutics. J Psychiatry Neurosci 31:296-297

Wood P, Cebak J, Baker G (2020) Metabolomics of rat brain after treatment with phenelzine: high-resolution mass spectrometric demonstration of increased brain levels of $\mathrm{N}$-acetyl amino acids. Neurol Neurobiol. https://doi.org/10.31487/j.NNB.2020.03.03

Wood P, Khan M, Moskal J (2007a) The concept of "aldehyde load" in neurodegenerative mechanisms: cytotoxicity of the polyamine degradation products hydrogen peroxide, acrolein, 3-aminopropanal, 3-acetamidopropanal and 4-aminobutanal in a retinal ganglion cell line. Brain Res 1145:150-156. https://doi.org/10. 1016/j.brainres.2006.10.004

Wood P, Wood J (2013) Thiol metabolism in schizophrenia: current status. Curr Psychiatry Rev 9:136-147

Wood PL (2003) Microglia: roles of microglia in chronic neurodegenerative diseases. In: Wood PL (ed) Neuroinflammation. Mechanisms and management, 2nd edn. Humana Press, Totowa, pp 3-27

Wood PL, Khan MA, Kulow SR, Mahmood SA, Moskal JR (2006a) Neurotoxicity of reactive aldehydes: the concept of "aldehyde load" as demonstrated by neuroprotection with hydroxylamines. Brain Res 1095:190-199. https://doi.org/10.1016/j.brainres. 2006.04.038

Wood PL, Khan MA, Moskal JR (2007b) Cellular thiol pools are responsible for sequestration of cytotoxic reactive aldehydes: central role of free cysteine and cysteamine. Brain Res 1158:158 163. https://doi.org/10.1016/j.brainres.2007.05.007

Wood PL, Khan MA, Moskal JR, Todd KG, Tanay VA, Baker G (2006b) Aldehyde load in ischemia-reperfusion brain injury: neuroprotection by neutralization of reactive aldehydes with 
phenelzine. Brain Res 1122:184-190. https://doi.org/10.1016/j. brainres.2006.09.003

Xiao M, Zhong H, Xia L, Tao Y, Yin H (2017) Pathophysiology of mitochondrial lipid oxidation: role of 4-hydroxynonenal (4-HNE) and other bioactive lipids in mitochondria. Free Radic Biol Med 111:316-327. https://doi.org/10.1016/j.freeradbiomed.2017.04. 363

Xu L, Hilliard B, Carmody RJ, Tsabary G, Shin H (2003) Arginase and autoimmune inflammation in the central nervous system. Immunology 110:141-148

Yadav UC, Ramana KV (2013) Regulation of NF-кB-induced inflammatory signaling by lipid peroxidation-derived aldehydes. Oxid Med Cell Longev 2013:690545. https://doi.org/10.1155/2013/ 690545

Yang L (2004) Calcineurin-mediated BAD Ser155 dephosphorylation in ammonia-induced apoptosis of cultured rat hippocampal neurons. Neurosci Lett 357:73-75. https://doi.org/10.1016/j.neulet. 2003.12.032

Yang L, Omori K, Omori K, Otani H, Suzukawa J, Inagaki C (2003) GABAC receptor agonist suppressed ammonia-induced apoptosis in cultured rat hippocampal neurons by restoring phosphorylated BAD level. J Neurochem 87:791-800. https://doi.org/10.1046/j. 1471-4159.2003.02069.x

Yoon B-E, Woo J, Chun Y-E et al (2014) Glial GABA, synthesized by monoamine oxidase B, mediates tonic inhibition. J Physiol 592(22):4951-4968

Youdim MB, Amit T, Bar-Am O, Weinreb O, Yogev-Falach M (2006) Implications of co-morbidity for etiology and treatment of neurodegenerative diseases with multifunctional neuroprotectiveneurorescue drugs; ladostigil. Neurotox Res 10:181-192

Youdim MBH, Bakhle YS (2006) Monoamine oxidase: isoforms and inhibitors in Parkinson's disease and depressive illness. Br J Pharmacol 147(Suppl 1):S287-S296. https://doi.org/10.1038/ sj.bjp.0706464

Young LT (2002) Neuroprotective effects of antidepressant and mood stabilizing drugs. J Psychiatry Neurosci 27:8-9

Yu PH, Wright S, Fan EH, Lun ZR, Gubisne-Harberle D (2003) Physiological and pathological implications of semicarbazide-sensitive amine oxidase. Biochim Biophys Acta 1647:193-199

Zarkovic K (2003) 4-Hydroxynonenal and neurodegenerative diseases. Mol Asp Med 24:293-303. https://doi.org/10.1016/S00982997(03)00024-4

Zhang W, Davidson JR (2007) Post-traumatic stress disorder: an evaluation of existing pharmacotherapies and new strategies. Expert Opin Pharmacother 8:1861-1870. https://doi.org/10.1517/14656 566.8.12.1861

Zuliani G, Ranzini M, Guerra G et al (2007) Plasma cytokines profile in older subjects with late onset Alzheimer's disease or vascular dementia. J Psychiatr Res 41:686-693. https://doi.org/10.1016/j. jpsychires.2006.02.008

Publisher's Note Springer Nature remains neutral with regard to jurisdictional claims in published maps and institutional affiliations. 